\title{
MODIS-Based Remote Estimation of Absorption Coefficients of an Inland Turbid Lake in China
}

\author{
Qiao Chu ${ }^{1,2}$, Yuchao Zhang ${ }^{1,3, *}$, Ronghua Ma ${ }^{1,3} \mathbb{D}$, Minqi Hu ${ }^{1,2}$ and Yuanyuan Jing ${ }^{1,2}$ \\ 1 Key Laboratory of Watershed Geographic Sciences, Nanjing Institute of Geography and Limnology, \\ Chinese Academy of Sciences, Nanjing 210008, China; chuqiao17@mails.ucas.ac.cn (Q.C.); \\ rhma@niglas.ac.cn (R.M.); huminqi16@mails.ac.cn (M.H.); jingyuanyuan18@niglas.ac.cn (Y.J.) \\ 2 University of Chinese Academy of Sciences, Beijing 100049, China \\ 3 Jiangsu Collaborative Innovation Center of Regional Modern Agriculture \& Environmental Protection, \\ Huaiyin Normal University, Huai'an 223300, China \\ * Correspondence: yczhang@niglas.ac.cn; Tel.: +86-1395-184-5169
}

Received: 23 April 2020; Accepted: 10 June 2020; Published: 16 June 2020

\begin{abstract}
Optical complexity and various properties of Case 2 waters make it essential to derive inherent optical properties (IOPs) through an appropriate method. Based on field measured data of Lake Chaohu between 2009 and 2018, the quasi-analytical algorithm (QAA) was modified for the particular scenario of that lake to derive absorption coefficients based on the moderate-resolution imaging spectroradiometer (MODIS) bands. By changing the reference wavelength to longer ones and building a relationship between the value of spectral power for particle backscattering coefficient $(\mathrm{Y})$, suspended particulate matter (SPM), and above-surface remote-sensing reflectance $\left(\mathrm{R}_{\mathrm{rs}}\right)$, we improved the accuracy of the retrieval of total absorption coefficients. The absorption coefficients of gelbstoff and non-algal particulates $\left(\mathrm{a}_{\mathrm{dg}}\right)$ and absorption coefficients of phytoplankton $\left(\mathrm{a}_{\mathrm{ph}}\right)$ in Lake Chaohu were also derived by changing important parameters according to Lake Chaohu. The derived $\mathrm{a}_{\mathrm{ph}}$ tend to be bigger than measured $\mathrm{a}_{\mathrm{ph}}$ in this study, while derived $\mathrm{a}_{\mathrm{dg}}$ tend to be smaller than measured data. We also used the corrected MODIS surface reflectance product (MOD09/MYD09) to calculate the $\mathrm{a}_{\mathrm{ph}}(443), \mathrm{a}_{\mathrm{ph}}(645)$, and $\mathrm{a}_{\mathrm{ph}}(678)$ by the model proposed in this study. It shows that in summer and autumn, $\mathrm{a}_{\mathrm{ph}}$ tended to be higher in the northwestern part of Lake Chaohu, and were relatively lower in the spring and winter, which is similar to previous studies. Overall, our study provides an algorithm that is effectively used in the case of Lake Chaohu and applicable to the data obtained by MODIS, which can be used for further study to investigate the change law of absorption coefficients in long time series by applying MODIS data.
\end{abstract}

Keywords: inherent optical properties (IOPs); absorption coefficients; quasi-analytical algorithm (QAA); MODIS; Lake Chaohu

\section{Introduction}

The inversion of water color involves the derivation of inherent optical properties (IOPs) from apparent optical properties (AOPs). As a result, information about water constituents is retrieved from derived IOPs, such as concentrations of chlorophyll-a ( $\mathrm{Chl} a)$, suspended sediments, and colored, dissolved organic matter (CDOM).

Recent studies have emphasized the importance of retrieving IOPs through remote sensing. Variations in IOPs can precisely indicate changes in water constituents and mass. AOPs refer to the parameters that vary with the change of illumination conditions, including water-leaving radiance $\left(L_{w}\right)$, above-surface remote-sensing reflectance $\left(R_{r s}\right)$, and so on [1]. The IOPs and light field together determine the AOPs. The inversion of the IOPs can be achieved by using the related algorithms from 
the AOPs. $R_{r s}$ is one of the most important AOPs, which is determined by the IOPs of the water body and the geometric structure of the underwater light field. Through the IOPs (absorption and scattering), inherent nonlinear intrinsic correlations exist between the concentration of each component and the remote-sensing reflectance.

Solutions to accurately derive the optical properties remotely have been studied for many years, and scientists have proposed algorithms related to this subject. Empirical algorithms use certain regressions between the IOPs and the ratios of below-surface remote sensing reflectance $\left(r_{\mathrm{rs}}\right)$ or $\mathrm{R}_{\mathrm{rs}}$. The main advantage of such an algorithm is that data processing is simple and rapid, which is essential in retrieving information from satellite sensors. However, due to the lack of a certain physical foundation, empirical models often rely too much on field-measured data, which are limited by time and region. Therefore, the applicability of those algorithms may be limited and may result in errors in different areas [2]. A semi-analytical model is based on the radiative transfer equation between the water composition, IOPs, and AOPs. These algorithms are suitable for various water types and are much more accurate than empirical algorithms $[3,4]$. Based on the basic theory of optical properties and the spectral model of water bodies, the quantitative relationship between the substance concentration in water and the optical properties of the water body can be established, which is called an analytical model. This model can be used for the large-scale and long-term monitoring of water color and quality. However the theoretical research and data measurement in different waters have not reached a perfect, applicable level.

Extensive work has been conducted on the inversion of IOPs in China and abroad, and the inversion model has gradually progressed from the traditional empirical model to the semi-analytical model. Carder et al. [3,5] presented a moderate-resolution imaging spectroradiometer (MODIS) semi-analytical algorithm, which can use $\mathrm{R}_{\mathrm{rs}}$ to retrieve IOPs including absorption and backscattering coefficients. Hoge and Lyon [6,7] created a linear matrix inversion model by using $R_{\mathrm{rs}}$ at 412, 490, and $555 \mathrm{~nm}$ and retrieved the IOPs of the water body. Doerffer built a retrieval procedure of suspended particulate matter (SPM), chlorophyll, and gelbstoff concentration based on neutral network [8]. Lee et al. [9] investigated a quasi-analytical algorithm (QAA) that can retrieve IOPs by using multi-band $\mathrm{R}_{\mathrm{rs}}$ data. This algorithm is applicable to hyperspectral data and multi-band satellite sensor data that have been or will be launched, such as the coastal zone color scanner (CZCS), the sea-viewing, wide field-of-view sensor (SeaWiFS), and MODIS [9]. It is derived from the analytical, semi-analytical, and empirical formulas for oceanic and coastal waters. It was updated to QAA_v6 in the following years [10].

QAA is one of the mainstream models at present. It has the characteristics of high precision and fast operation speed and can be used to process large quantities of data. In recent years, many scholars in China have conducted research on the application of QAA in coastal waters in the country [11-13]. For inland Case 2 waters, whose optical properties are significantly influenced by mineral particles, CDOM, or microbubbles [14], Le et al. [15,16] validated and improved the QAA algorithm in Lake Taihu; the results showed that the reference wavelength has to be longer in turbid waters. Xie et al. [17] applied the QAA to the inversion of the IOPs of Lake Kuncheng. Domestic research on IOPs mainly focuses on the inversion of ocean IOPs and the backscattering coefficient of inland water, but the inversion of the absorption coefficient of inland water is less studied [18]. Although QAA is widely used, there are still many uncertainties in deriving optical properties for optically complex Case 2 waters $[16,19,20]$. Specifically, the reference wavelength and the empirical formulas do not work for inland Case 2 waters, especially for the case of Lake Chaohu, which is a lake of high turbidity, Chl $a$ concentrations, and complicated optical properties.

This study aimed to provide a solution to derive IOPs of Lake Chaohu by applying MODIS data. The time resolution of MODIS is effective for further study to investigate the change law of IOPs of Lake Chaohu in the long time series. In this paper, the derived absorption coefficients and measured absorption coefficients were compared and analyzed. Thereafter, some test data were used to measure 
the accuracy of this algorithm. We hope that this algorithm can provide a viable solution by applying remote sensing to the inversion of water color in Lake Chaohu or other turbid lakes.

\section{Data}

\subsection{Study Area}

Lake Chaohu $\left(31^{\circ} 25^{\prime}-31^{\circ} 43^{\prime} \mathrm{N}, 117^{\circ} 17^{\prime}-117^{\circ} 51^{\prime} \mathrm{E}\right.$, Figure 1) is an eutrophic and turbid shallow lake in Anhui Province, in the east of China, with an acreage of $770 \mathrm{~km}^{2}$ and an average depth of $3.0 \mathrm{~m}$ [21]. This lake is an important source of fish and drinking water for Hefei, a city under a subtropical monsoon climate (Figure 1). Lake Chaohu has a volume of $32.3 \times 10^{8} \mathrm{~m}^{3}$ during the rainy season for approximately five months and only $17.2 \times 10^{8} \mathrm{~m}^{3}$ during the dry season for approximately seven months [22]. Around 9 million people live around the lake, in which the main contamination sources are agricultural, industrial, and municipal pollution [23,24]. Lake Chaohu has had poor water quality and frequent algal blooms, particularly cyanobacteria blooms, over the past few decades [25].

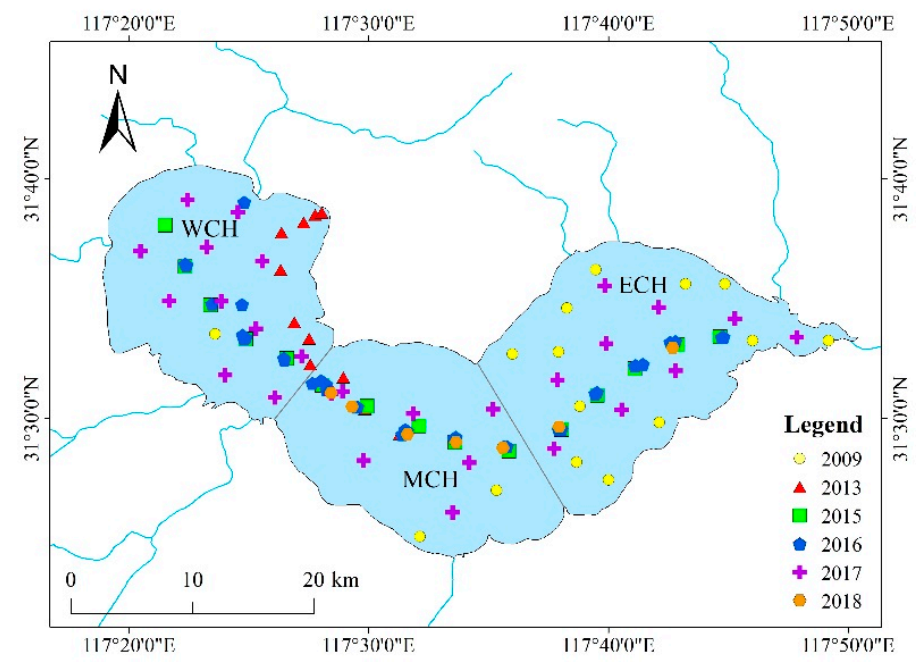

Figure 1. The study area and samples in Lake Chaohu, China, during 11 cruise surveys from October 2009 to July 2018.

\subsection{Sampling and Data Collection}

We conducted 11 cruise surveys, with 119 surface samples from October 2009 to July 2018 to measure optical properties in Lake Chaohu in this study (Figure 1). From this, 94 samples were used to build models and 25 samples were used as test data. We measured $R_{\mathrm{rs}}$ data at the sites. The water samples were kept at $4{ }^{\circ} \mathrm{C}$ in the dark before experiments of SPM, Chl $a$, dissolved organic carbon concentration (DOC), and absorption coefficients.

Measurements of Relevant Parameters

A handheld ASD (analytical spectral device) under the NASA Ocean Optics protocols was used to obtain $\mathrm{R}_{\mathrm{rs}}$ [26]. Applying the method described by Mobley et al. [27], the viewing direction was 40 degree from the nadir and 135 degree from the Sun.

We filtered the water samples by Whatman GF/C glass-fiber filters with a pore size of approximately $1.2 \mu \mathrm{m}$ and extracted pigments with a reference of $90 \%$ acetone. We used a Shimadzu UV-2600 (Kyoto, Japan) to measure the absorbance then achieved Chl $a$ data [28]. We pre-combusted Whatman GF/F glass-fiber filters with a pore size of $0.7 \mu \mathrm{m}$ at $450{ }^{\circ} \mathrm{C}$ for $6 \mathrm{~h}$ and pre-weighed them. We then filtered the water samples and dried them at high temperature $\left(105^{\circ} \mathrm{C}\right)$ for approximately $4-6 \mathrm{~h}$ for the measurement of SPM concentrations. Suspended particulate inorganic matter (SPIM) was similarly measured through weighing the filters before and after burning organic matter for $6 \mathrm{~h}$ [29]. 
The absorption coefficients of total particulate matter, absorption coefficients of non-algal particulate $\left(\mathrm{a}_{\mathrm{d}}\right)$, and absorption coefficients of phytoplankton $\left(\mathrm{a}_{\mathrm{ph}}\right)$ at 350-800 nm were obtained by using the same machine with GF/F filters [26]. The baseline was obtained by a blank filter with distilled water [2]. The $\mathrm{a}_{\mathrm{d}}$ was measured after the pigments were bleached with sodium hypochlorite, and then $\mathrm{a}_{\mathrm{ph}}$ were derived. The absorption coefficient of CDOM $\left(\mathrm{ag}_{\mathrm{g}}\right)$ was measured using the same machine with Milli-Q water as the reference from water filtered by filters with a $0.22-\mu \mathrm{m}$ pore size from 280 to $700 \mathrm{~nm}$ (1-nm interval) [2,30,31].

\subsection{Satellite Image Data Preprocessing}

In this study, MODIS data were selected as input data. MODIS has high spectral and time resolutions. It is set on Terra and Aqua and has five levels of data products. MODIS provides continuous global remote sensing data that have a wide range of applications in ecology and geography research. The MODIS data preprocessing in this study mainly refer to the geometric correction and atmospheric correction of the MODIS surface reflectance product (MOD09/MYD09) in Lake Chaohu.

\subsubsection{The MOD09/MYD09 Product}

The MOD09/MYD09 surface reflectance product can be used in the calculation of the Earth's surface albedo $[32,33]$. It belongs to the terrestrial product and corresponds to the Terra and Aqua satellites, respectively. MOD09/MYD09 has reflectance data with 250-m resolution of Bands 1 and 2 (620-670 nm and 841-876 nm), 500-m resolution of Bands 1-7 (620-670 nm, 841-876 nm, 459-479 $\mathrm{nm}, 545-565 \mathrm{~nm}, 1230-1250 \mathrm{~nm}, 1628-1652 \mathrm{~nm}$, and 2105-2155 nm), 1-km resolution of Bands 1-16 (620-670 nm, 841-876 nm, 459-479 nm, 545-565 nm, 1230-1250 nm, 1628-1652 nm, 2105-2155 nm, $405-420 \mathrm{~nm}, 438-448 \mathrm{~nm}, 483-493 \mathrm{~nm}, 526-536 \mathrm{~nm}, 546-556 \mathrm{~nm}, 662-672 \mathrm{~nm}, 673-683 \mathrm{~nm}, 743-753 \mathrm{~nm}$, and 862-877 nm), multi-resolution pixel state QA (quality assessment) data, and 1-km observation statistics. In the QA data, the type of ground cover is indicated. MOD09/MYD09 data (hereinafter referred to as MOD09) are based on Level1B data, which are corrected for the effects of low atmospheric gases and aerosols. Atmospheric correction aims to remove the impact of Sun glint, residual aerosol scattering, and so on. Given the requirements of lake water bodies for reflectance data, MOD09 data are still insufficient for Case 2 water body monitoring. In order to eliminate residual effects, further correction is needed.

\subsubsection{The MOD09 Correction Method}

The atmosphere is an important factor affecting the quantitative analysis and application of remote sensing. Therefore, removing the effects of atmospheric scattering and absorption from the radiance value received by the sensor has become the premise of remote sensing quantitative analysis. In some studies, MOD09 reflectance data are used directly [34-36]. Nevertheless, by comparing MOD09 data and measured data, it has been found that the MOD09 data generally show higher phenomena in some bands compared with the measured data [37].

In this study, we used a simple correction method based on near-infrared (NIR) and short-wave infrared (SWIR) bands [37]. The advantage of using this correction method is that it can eliminate the noise in MOD09 data by simple correction and then convert the surface reflectance to the scale of remote-sensing reflectance, so that a more accurate $R_{\mathrm{rs}}(\lambda)$ is obtained and can be more easily applied to processing. The specific correction method is as follows:

$$
\mathrm{R}_{\mathrm{rS}}(\lambda)=\frac{\mathrm{R}(\lambda)-\min \left(\mathrm{R}_{\mathrm{NIR}}: \mathrm{R}_{\mathrm{SWIR}}\right)}{\pi}
$$

where min ( $\left.R_{N I R}: R_{S W I R}\right)$ refers to the minimum reflectance value of NIR and SWIR bands. Due to the strong absorption of water in the NIR and SWIR bands, reflectance will generally drop to 0 in the NIR band in the case of general water, while reflectance will generally decrease to 0 in the SWIR band in the 
case of turbid water [38]. Therefore, the reflectance value of the NIR and SWIR bands is considered as additive noise. The additive noise can be eliminated by subtracting the value from each band value.

After the correction by this method, there are still some gaps between the corrected $R_{\mathrm{rs}}$ and the measured values at $748 \mathrm{~nm}$ (Figure 2a).Therefore, this study used the least-square method to calibrate the values at $748 \mathrm{~nm}$, again based on the measured data. The equation between the measured $R_{r s}$ and the values derived from MOD09 is constructed to make the values closer to the measured data. The $R_{r s}$ after recalibration is shown in Figure $2 b(N=79)$. Similarly, the $R_{r s}$ values at 413 and 443 nm were also corrected again using this method.
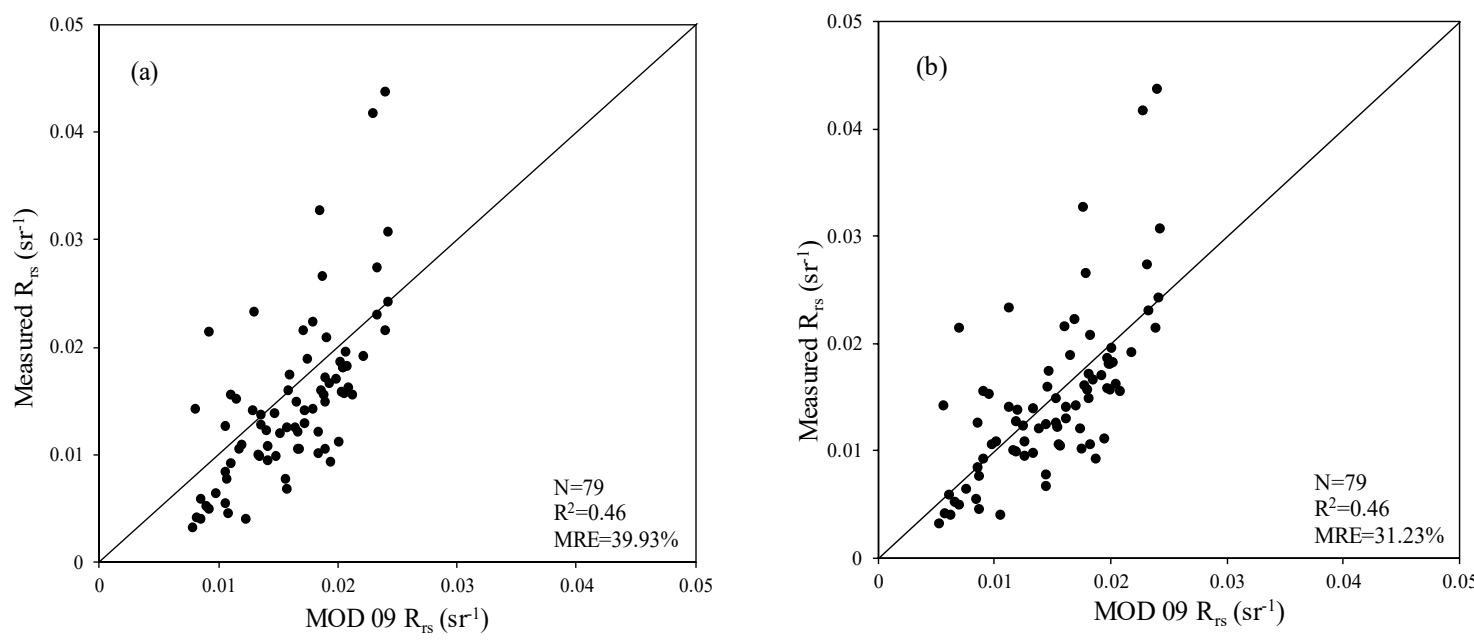

Figure 2. Measured above-surface remote-sensing reflectance $\left(\mathrm{R}_{\mathrm{rs}}\right)$ and $\mathrm{R}_{\mathrm{rs}}$ derived from MODIS surface reflectance product (MOD09) at $748 \mathrm{~nm}$ (a) before recalibration and (b) after recalibration.

\section{Improving QAA}

QAA is a semi-analytical method for calculating the absorption coefficient and backscattering coefficient of water proposed by Lee et al. [9]. The inversion process of QAA has two parts. The first one is deriving the total absorption coefficient and backscattering coefficient. The second, utilizing the coefficient of the total absorption obtained from the first part, is decomposing the total absorption coefficient into different elements. The QAA algorithm is proposed for open ocean and coastal waters; accordingly, some empirical formulas are used for specific research areas, which cannot be directly applied to the inversion of the absorption coefficients for inland Case 2 waters.

\subsection{Inversion of Total Absorption Coefficients}

In the first part of QAA, a relationship between $\mathrm{R}_{\mathrm{rs}}$ and total absorption coefficients was established. Similarly in this study, a new relationship needs to be established according to Lake Chaohu by changing some parameters and formulas as follows.

3.1.1. Values of $g_{0}$ and $g_{1}$

$$
\mathrm{u}(\lambda)=\frac{-\mathrm{g}_{0}+\left[\left(\mathrm{g}_{0}\right)^{2}+4 \mathrm{~g}_{1} \mathrm{r}_{\mathrm{rs}}(\lambda)\right]^{1 / 2}}{2 \mathrm{~g}_{1}}
$$

The ratio of backscattering coefficient to the sum of absorption and backscattering coefficients $(\mathrm{u}(\lambda))$ is calculated by $\mathrm{r}_{\mathrm{rs}}$ and $\mathrm{g}_{0}, \mathrm{~g}_{1}$. Gordon et al. [39] found the values of $\mathrm{g}_{0}=0.0949$ and $\mathrm{g}_{1}=0.0794$ for oceanic Case 1 waters, whose optical properties are determined primarily by phytoplankton, CDOM, and detritus degradation products [40]. Lee et al. $[9,41]$ advised that $\mathrm{g}_{0}=0.084$ and $\mathrm{g}_{1}=0.17$ is more accurate for higher-scattering coastal waters. In fact, the values of $g_{0}$ and $g_{1}$ are different because they depend on the particle phase function, which cannot be measured remotely. The values of these 
two parameters have to be estimated before being used in semi-analytical algorithms. Lee [9] used the averaged $g_{0}$ and $g_{1}$ values, which can be applied to coastal and open ocean waters. However, the values of $g_{0}$ and $g_{1}$ have a minimal influence on the inversion accuracy of the total absorption coefficient. Therefore, in this study, after trying to apply different values, we used the values of $g_{0}$ of 0.08945 and $\mathrm{g}_{1}$ of 0.1247 as in the QAA original algorithm, which is suitable for more types of waters.

\subsubsection{Reference Wavelength}

The measurements of absorption coefficients of water constituents include $a_{p h}(\lambda)$, $a_{d}(\lambda)$, and $a_{g}(\lambda)$. The total absorption coefficient $\mathrm{a}(\lambda)$ is the sum of $\mathrm{a}_{\mathrm{ph}}(\lambda), \mathrm{a}_{\mathrm{d}}(\lambda), \mathrm{a}_{\mathrm{g}}(\lambda)$, and the absorption coefficient of pure water $\mathrm{a}_{\mathrm{w}}(\lambda)[42]$.

$$
\mathrm{a}(\lambda)=\mathrm{a}_{\mathrm{ph}}(\lambda)+\mathrm{a}_{\mathrm{d}}(\lambda)+\mathrm{ag}_{\mathrm{g}}(\lambda)+\mathrm{a}_{\mathrm{w}}(\lambda)
$$

The principle of selecting the reference wavelength in Step 2 (QAA) is that the absorption coefficient of pure water is dominant at the reference wavelength, and $\mathrm{a}_{\mathrm{w}}\left(\lambda_{0}\right)$ can basically replace $\mathrm{a}\left(\lambda_{0}\right)$. Table 1 provides examples of reference wavelengths in some relevant studies.

Table 1. Reference wavelengths from different cases of waters.

\begin{tabular}{ccc}
\hline Reference Wavelength & Areas & Reference \\
\hline $555 \mathrm{~nm}$ & oligotrophic waters & {$[9]$} \\
$640 \mathrm{~nm}$ & mesotrophic waters & {$[9]$} \\
$695 \mathrm{~nm}$ & high-absorbing waters & {$[17]$} \\
$715 \mathrm{~nm}$ & Lake Kuncheng & {$[15,43]$} \\
\hline
\end{tabular}

According to the basic water quality in Lake Chaohu, $\mathrm{a}_{\mathrm{w}}$ increases and $\mathrm{a}_{\mathrm{g}}$ and $\mathrm{a}_{\mathrm{ph}}$ tend to decrease to 0 around $700 \mathrm{~nm}$. Therefore, the reference wavelengths should be around $700 \mathrm{~nm}[43,44]$. In our study, on the basis of the center wavelengths of MODIS bands, three reference wavelengths (645, 678, and $748 \mathrm{~nm}$ ) were used to derive the total absorption coefficients of three different samples (Figure 3), which represent three kinds of water, namely, turbid, eutrophic, and general water. The turbid water has high SPM concentration (SPM concentration $=93 \mathrm{mg} / \mathrm{L})$, the eutrophic water has high Chl $a$ concentration $(\mathrm{Chl} a$ concentration $=183.39 \mu \mathrm{g} / \mathrm{L})$ and the SPM and Chl $a$ concentrations of general water are not high $(\mathrm{SPM}$ concentration $=27 \mathrm{mg} / \mathrm{L}, \mathrm{Chl} a$ concentration $=17.04 \mu \mathrm{g} / \mathrm{L})$. As the graphs suggest, in the case of using $748 \mathrm{~nm}$ as reference wavelength, the derived total absorption coefficients are much closer to the measured total absorption coefficients. We can conclude that, regardless of the type of water, setting $748 \mathrm{~nm}$ as the reference wavelength is most suitable for Lake Chaohu.
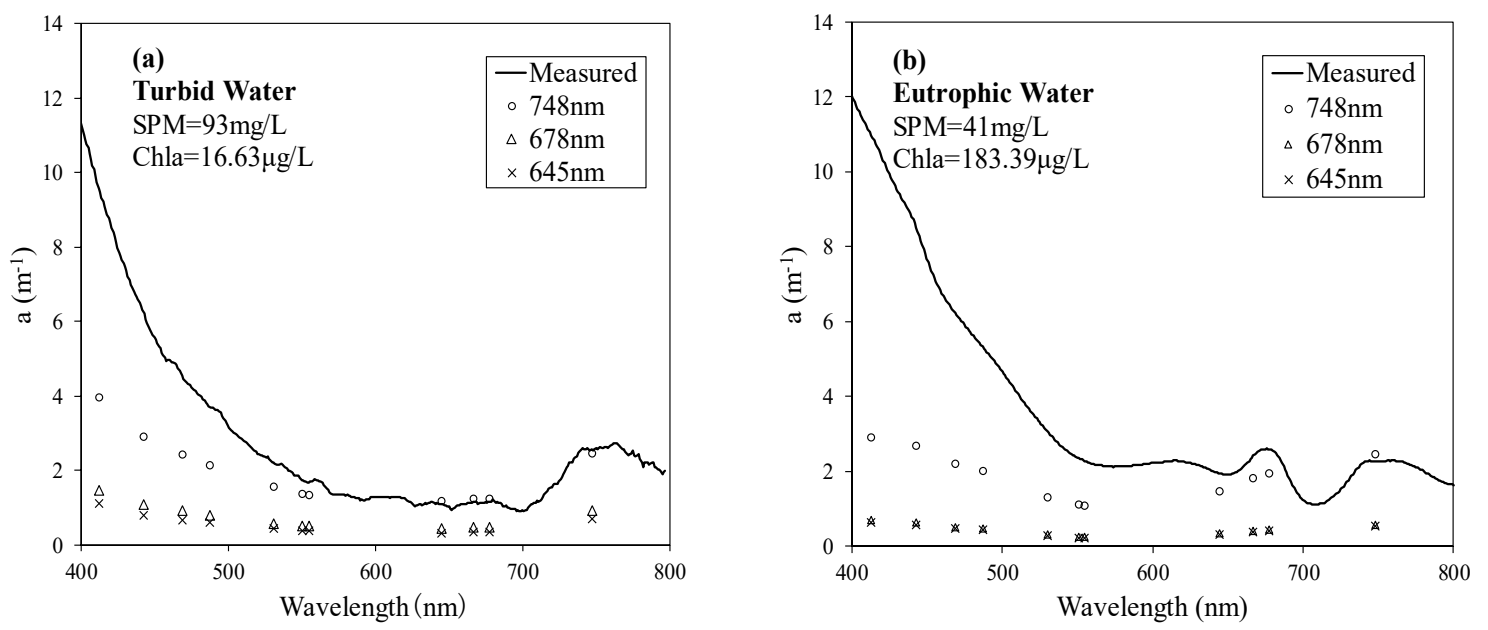

Figure 3. Cont. 


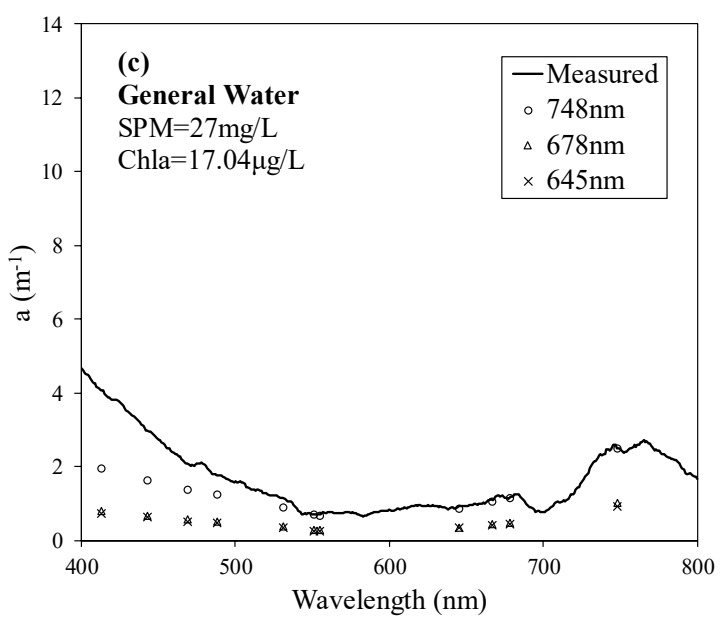

Figure 3. Comparison of measured total absorption coefficients with derived values of different reference wavelengths in (a) turbid, (b) eutrophic, and (c) general water.

\subsubsection{Model to Estimate the Power Value Y}

Power value $Y$ is a parameter used to estimate the backscattering coefficients at different wavelengths. If $\mathrm{a}\left(\lambda_{0}\right), \mathrm{u}\left(\lambda_{0}\right)$, and backscattering coefficients of pure water at wavelength $\lambda_{0}\left(\mathrm{~b}_{\mathrm{bw}}\left(\lambda_{0}\right)\right)$ are available, and the value of $Y$ is estimated, then backscattering coefficients of particulate at wavelength $\lambda_{0}\left(\mathrm{~b}_{\mathrm{bp}}\left(\lambda_{0}\right)\right)$ can be efficiently obtained. The values of total backscattering coefficient at wavelength $\lambda$ $\left(b_{b}(\lambda)\right)$ at all wavelengths are then derived. As shown in Table 2, different types of waters have different ranges of $Y$ based on different reference wavelengths. A model to estimate the value of wavelength exponent $\mathrm{Y}$ in the case of Lake Chaohu should be established in this study.

Table 2. Power value $Y$ of different types of waters.

\begin{tabular}{cccc}
\hline $\mathbf{Y}$ & Areas & Methods & Reference \\
\hline 1.32-2.8 & Lake Taihu & $\begin{array}{c}\text { The initial value of } \mathrm{Y} \text { is set to 0.1, and the } \\
\text { step size is set to } 0.1 \text { for iteration, and then } \\
\text { the data was used in calculation. } \\
\text { The backscattering coefficient is calculated } \\
\text { based on measured data. } \\
\text { Huanghai Sea } \\
\text { East China Sea } \\
\text { Lake Taihu }\end{array}$ & $\begin{array}{c}\text { Measured data are used to calculate the } \\
\text { backscattering coefficient. } \\
\text { The empirical model of the } \mathrm{Y} \text { value is } \\
\text { established by simulating the relationship } \\
\text { between the reference } \mathrm{Y} \text { value and } \\
\text { reflectance ratio } \mathrm{r}_{\mathrm{rs}}(640) / \mathrm{r}_{\mathrm{rs}}(715) .\end{array}$ \\
\hline
\end{tabular}

As no backscattering coefficient was measured in our research, the real $Y$ value cannot be simulated by the original analytical model. Therefore, our research used the method of iteration [15]. We made $Y$ iterate from 0.1 to 3 (step size of 0.1). When the minimum average absolute error (MAE) between the calculated total absorption coefficients and the measured total absorption coefficients at MODIS bands between 400 and $700 \mathrm{~nm}$ was less than 0.3 , the best reference $Y$ value of this sample was obtained. Figure 4 represents reference $Y$ values of three different samples. The accuracy of the calculation results was greatly improved in the three cases mentioned.

To obtain the reference $Y$ value as accurately as possible, we had to establish a model for estimating $Y$. The $Y$ value is related to parameters, such as $R_{r s}$, and concentrations of water compositions. First, we found out that a very good correlation did not exist between the ratio of $R_{r s}$ and $Y$ by applying measured data of Lake Chaohu. Thus, the relationships between the reference $Y$ value and certain water quality parameters were established (Figure 5). As the graphs show, the relationship between SPM 
concentration and $Y$ value had the best correlation. Therefore, this model $(Y=0.0103 * S P M+1.6386)$ $(\mathrm{N}=80)$ was used in our algorithm.
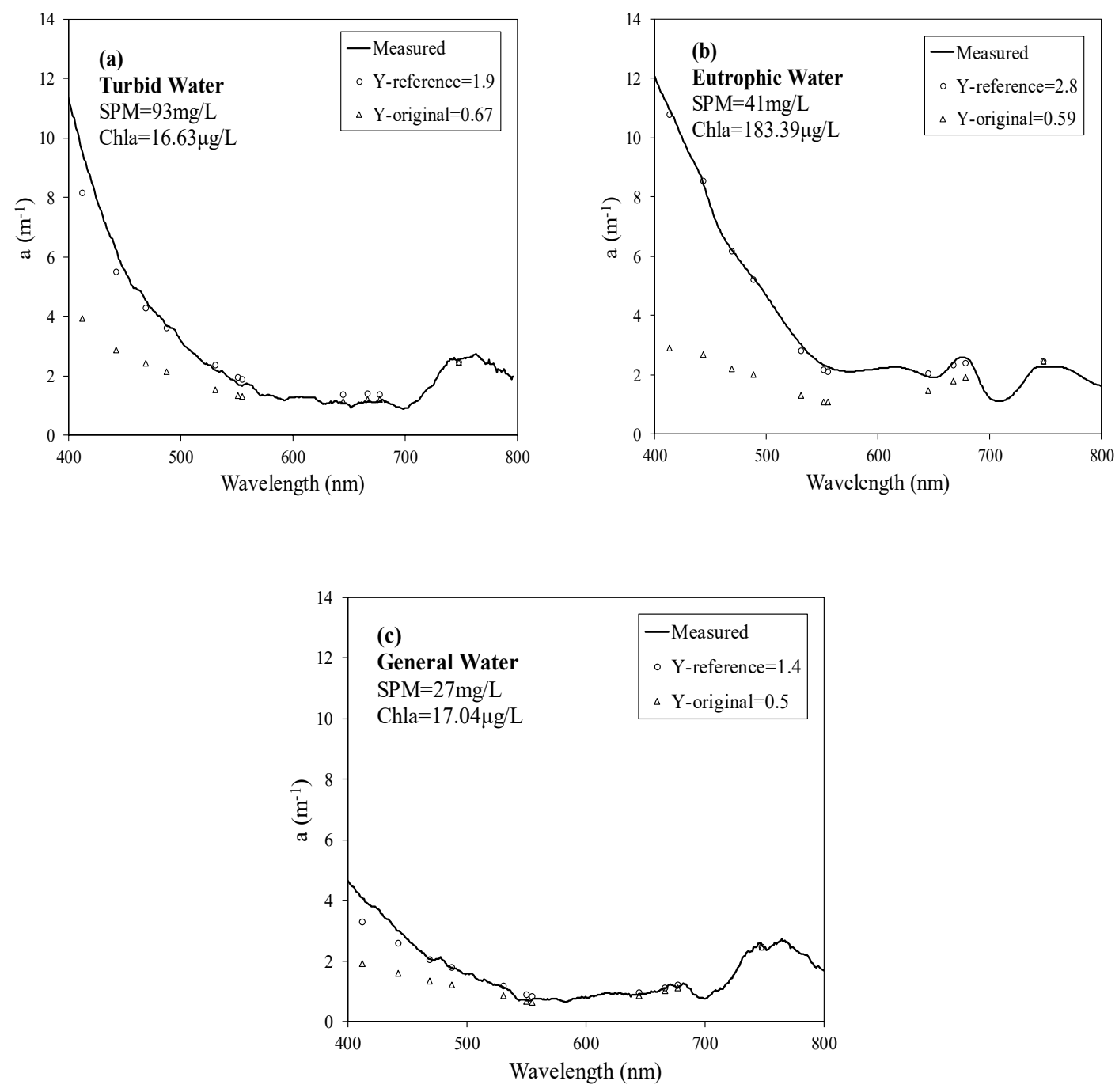

Figure 4. Comparison of measured total absorption coefficients with derived values of different $\mathrm{Y}$ values in the cases of (a) turbid, (b) eutrophic, and (c) general water.

Even though the relationship between the $\mathrm{Y}$ value and SPM is modeled, water quality parameters cannot be determined from previous calculations. Thus, the model of SPM concentration and $R_{r s}$ should be built. Based on several references, the general characteristics of SPM inversion algorithms are presented in Table 3. In this study, similar methods were used to construct the relationship between $R_{r s}$ and SPM concentration. We found that SPM concentration and $R_{r s}(555) / R_{r s}(748)$ had the best correlation (Figure 6).

Table 3. General characteristics of SPM inversion algorithms.

\begin{tabular}{ccc}
\hline Models & Areas & Reference \\
\hline $\mathrm{SPM}=-1.91+1140.25 * \mathrm{R}_{\mathrm{rs}}(645)$ & Biloxi Bay & {$[47]$} \\
$\mathrm{SPM}=9.65 * \exp \left(58.81 * \mathrm{R}_{\mathrm{rs}}(645)\right)$ & Lake Taihu & {$[48]$} \\
$\ln (\mathrm{SPM})=\left(\mathrm{R}_{\mathrm{rs}}(840) / \mathrm{R}_{\mathrm{rs}}(545)+0.9614\right) / 0.3193$ & Gironde & {$[49]$} \\
$\mathrm{SPM}=349.83 * \mathrm{R}_{\mathrm{rs}}(645)+2.9663$ & Muuga Port & {$[50]$} \\
\hline
\end{tabular}



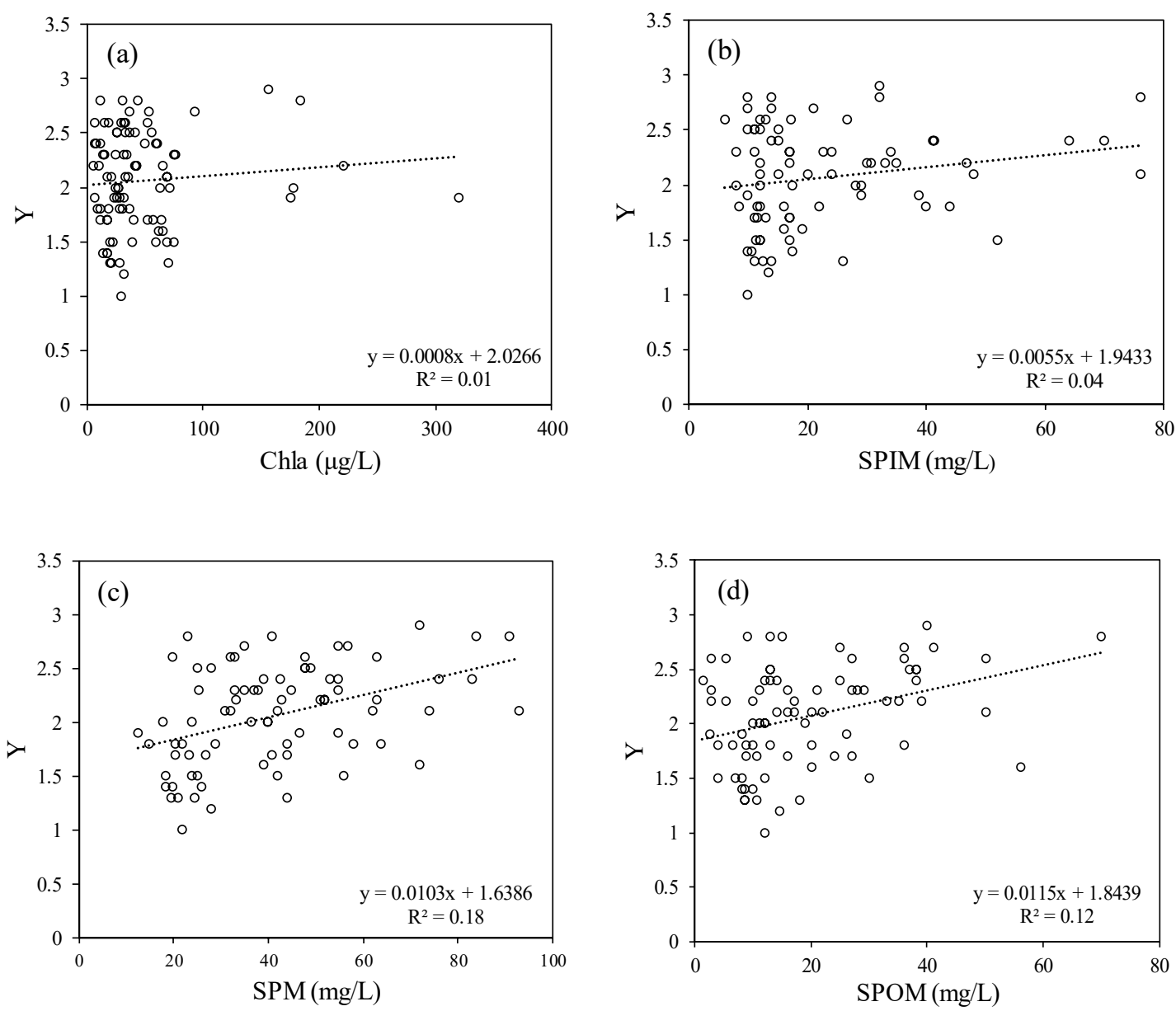

Figure 5. Relationships between $\mathrm{Y}$ values and the following water quality parameters, based on measured data: (a) chlorophyll-a (Chl a), (b) suspended particulate inorganic matter (SPIM), (c) suspended particulate matter (SPM), and (d) suspended particulate organic matter (SPOM).

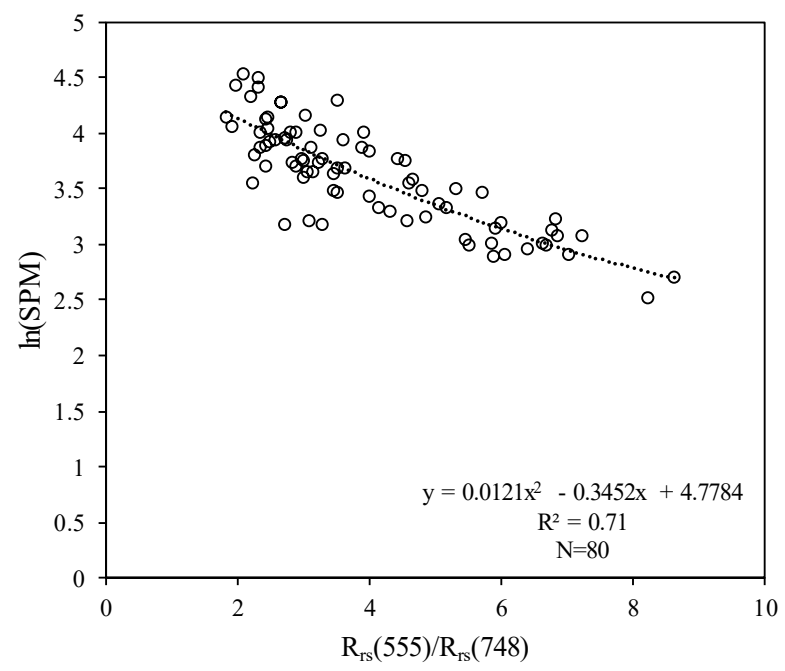

Figure 6. Model of SPM concentration and $\mathrm{R}_{\mathrm{rs}}(555) / \mathrm{R}_{\mathrm{rs}}(748)$ based on measured data.

\subsection{Decomposition of Total Absorption Coefficient}

Deriving $\mathrm{a}_{\mathrm{ph}}(\lambda)$ and the absorption coefficients of gelbstoff and non-algal particulates $\left(\mathrm{a}_{\mathrm{dg}}(\lambda)\right)$ from the total absorption coefficients $(\mathrm{a}(\lambda))$ is a major challenge because the total absorption coefficient is the sum of $a_{w}, a_{p h}, a_{d}$, and $a_{g}$. Lee has developed an empirical algorithm for the separation [9]. 
We should estimate two parameters first: $\zeta$, which is equal to $a_{p h}(410) / a_{p h}(440)$, and $\xi$, which amounts to $\mathrm{a}_{\mathrm{dg}}(410) / \mathrm{a}_{\mathrm{dg}}(440)$. The value of $\zeta$ is obtained using the ratio of measured $\mathrm{r}_{\mathrm{rs}}(440) / \mathrm{r}_{\mathrm{rs}}(555)$ data in the QAA algorithm.

\subsubsection{The Value of Spectral Slope of $\mathrm{a}_{\mathrm{dg}}$ Spectrum (S)}

The spectral slope of $a_{d g}$ spectrum (S) can depict the spectral shape of $a_{d g}(\lambda)$, which is the sum of $\mathrm{a}_{\mathrm{g}}(\lambda)$ and $\mathrm{a}_{\mathrm{d}}(\lambda)$. In the original QAA process, $S$ was valued at $0.015 \mathrm{~nm}^{-1}$. The measured data of $\mathrm{a}_{\mathrm{dg}}(410)$ and $\mathrm{a}_{\mathrm{dg}}(440)$ in Lake Chaohu were used to calculate $\mathrm{S}$. We concluded that the average value of $S$ is 0.01453 , and the standard deviation is 0.001129 , which means that all the values are basically distributed around the average. Therefore, we selected the mean, 0.01453 , as the value of $S$ in our study.

\subsubsection{The Relationship of $\mathrm{a}_{\mathrm{ph}}$ and $\mathrm{r}_{\mathrm{rs}}$}

The value of $a_{\mathrm{ph}}(410) / \mathrm{a}_{\mathrm{ph}}(440)$ is calculated from the ratio of $\mathrm{r}_{\mathrm{rs}}(440) / \mathrm{r}_{\mathrm{rs}}(555)$ through an empirical formula in the original QAA algorithm [9]. Considering the research area, we had to rebuild the relationship between $a_{p h}$ and $r_{r s}$ by simulating the relationship between the $a_{p h}(410) / a_{p h}(440)$ and the spectral ratio $r_{r s}$ of the center wavelengths of MODIS bands between 400 and $800 \mathrm{~nm}$. The model was constructed using $\mathrm{r}_{\mathrm{rs}}(645) / \mathrm{r}_{\mathrm{rs}}(678)$ with a high correlation, as shown in Figure 7.

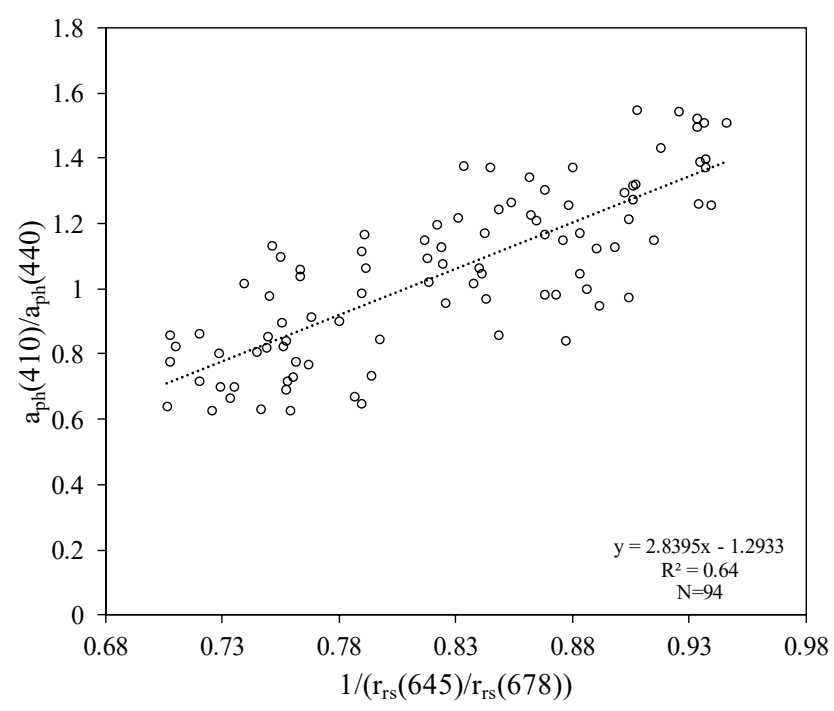

Figure 7. Model of relationship of below-surface remote sensing reflectance $\mathrm{r}_{\mathrm{rs}}(645) / \mathrm{r}_{\mathrm{rs}}(678)$ with absorption coefficients of phytoplankton $\mathrm{a}_{\mathrm{ph}}(410) / \mathrm{a}_{\mathrm{ph}}(440)$.

The specific calculation process of this improved QAA is as follows (Table 4).

To evaluate the performance of this algorithm and the accuracy of the MOD09 data after correction, three parameters were calculated.

The accuracy evaluation indicators used in this study include average relative error (MRE) [51], average absolute error (MAE) and root mean square error (RMSE) [52]. The expression equations are as follows:

$$
\begin{gathered}
\text { MRE }=\frac{1}{N} \sum_{i=1}^{N}\left|\frac{y_{i}-x_{i}}{x_{i}}\right| \\
\text { MAE }=\frac{1}{N} \sum_{i=1}^{N}\left|y_{i}-x_{i}\right| \\
\text { RMSE }=\sqrt{\frac{1}{N} \sum_{i=1}^{N}\left(y_{i}-x_{i}\right)^{2}}
\end{gathered}
$$


where $x$ represents the measured value, $y$ represents the derived value, and $\mathrm{N}$ represents the number of samples. Coefficient of determination $\left(\mathrm{R}^{2}\right)$ was also used to assess the accuracy of the model.

Table 4. Steps of the improved quasi-analytical algorithm (QAA).

\begin{tabular}{ccc}
\hline Step & Formula & Approach \\
\hline 0 & $r_{r s}=R_{r s} /\left(0.52+1.7 R_{r s}\right)$ & Semi-analytical \\
1 & $u(\lambda)=\frac{-g_{0}+\left[\left(g_{0}\right)^{2}+4 g_{1} r_{r s}(\lambda)\right]^{1 / 2}}{2 g_{1}}$ & Semi-analytical \\
2 & $\mathrm{a}(748)=a_{w}(748)$ & Empirical \\
3 & $b_{b p}(748)=\frac{u(748) a(748)}{1-u(748)}-b_{b w}(748)$ & Analytical \\
4 & $\mathrm{Y}=0.0103 * \exp \left[0.0121\left(R_{r s}(555) / R_{r s}(748)\right)^{2}-0.3452\left(R_{r s}(555) / R_{r s}(748)\right)+4.7784\right]+1.6386$ & Empirical \\
5 & $b_{b p}(\lambda)=b_{b p}(748)\left(\frac{748}{\lambda}\right)^{Y}$ & Semi-analytical \\
6 & $\mathrm{a}(\lambda)=\frac{[1-u(\lambda)]\left[b_{b w}(\lambda)+b_{b p}(\lambda)\right]}{u(\lambda)}$ & Analytical \\
7 & $\zeta=\frac{a_{p h}(410)}{a_{p h}(440)}=\frac{2.8395}{r_{r s}(645) / r_{r s}(678)}-1.2933$ & Empirical \\
8 & $\xi=\frac{a_{d g}(410)}{a_{d g}(440)}=\exp [S(440-410)]$ & Semi-analytical \\
9 & $a_{d g}(440)=\frac{a(410)-\zeta \mathrm{a}(440)}{\xi-\zeta}-\frac{a_{w v}(410)-\zeta a_{w i}(440)}{\xi-\zeta}$ & Analytical \\
10 & $a_{p h}(440)=a(440)-a_{d g}(440)-a_{w w}(440)$ & Analytical \\
\hline
\end{tabular}

\section{Results and Validation}

\subsection{MODIS Corrected Data Accuracy Evaluation}

Compared with the measured $R_{r s}$ data, the errors of the $R_{r s}$ derived from MOD09 product were evaluated in this paper. Before correction, as shown in Figure $8 \mathrm{a}$, most of the 79 points of $\mathrm{R}_{\mathrm{rs}}$ were above the 1:1 line, indicating that, on the same scale, the data at $413,443,469,555,645,678$, and 748 $\mathrm{nm}$ were generally larger than the measured data; after using this correction method, as shown in Figure $8 b$, the $R_{r s}$ of the points generally had a good linear correlation. The scatterplots were mostly distributed near the 1:1 line. At the wavelength $748 \mathrm{~nm}$, the corrected values were still a little higher than the measured data. Tables 5 and 6 show the statistics of the errors before and after correction. The MRE at $413 \mathrm{~nm}$ was reduced from $76.46 \%$ to $30.02 \%$, and the RMSE was from $0.012 \mathrm{sr}^{-1}$ to $0.005 \mathrm{sr}^{-1}$. The MRE value before correction at the 555-nm band was $13.83 \%$, while the MRE value after correction was only $9.23 \%$. The MRE of $748 \mathrm{~nm}$ before correction was as high as $84.66 \%$, while the MRE after correction was $31.23 \%$, and the RMSE also decreased from $0.009 \mathrm{sr}^{-1}$ to $0.006 \mathrm{sr}^{-1}$. Compared with the original MOD09, the RMSEs and MREs of the corrected MOD09 at all bands were significantly reduced. This shows that the correction method we used in this study can obtain more accurate $R_{r s}$.
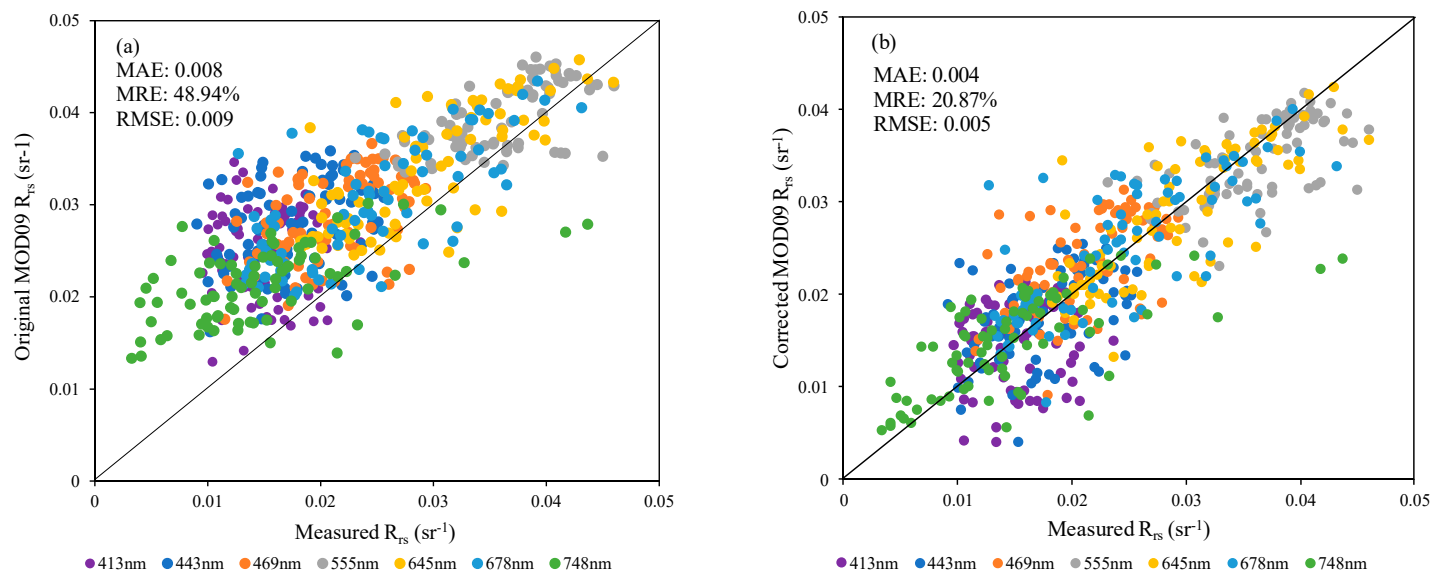

Figure 8. Scatterplots of $R_{r s}$ derived from (a) original and (b) corrected MOD09 compared with measurements in different bands. 
Table 5. Error statistics of $\mathrm{R}_{\mathrm{rs}}$ derived from the original MOD09.

\begin{tabular}{ccc}
\hline Wavelength (nm) & MRE (\%) & RMSE (sr $^{-1}$ ) \\
\hline 413 & 76.46 & 0.012 \\
443 & 68.35 & 0.012 \\
555 & 13.83 & 0.005 \\
645 & 21.24 & 0.006 \\
678 & 34.95 & 0.008 \\
748 & 84.66 & 0.009 \\
\hline
\end{tabular}

Table 6. Error statistics of $\mathrm{R}_{\mathrm{rs}}$ derived from the corrected MOD09.

\begin{tabular}{ccc}
\hline Wavelength (nm) & MRE (\%) & RMSE (sr $\mathbf{~}^{\mathbf{1})}$ \\
\hline 413 & 30.02 & 0.005 \\
443 & 24.15 & 0.005 \\
555 & 9.23 & 0.004 \\
645 & 11.50 & 0.005 \\
678 & 17.51 & 0.005 \\
748 & 31.23 & 0.006 \\
\hline
\end{tabular}

\subsection{Inversion of Absorption Coefficients in Different Water Types}

The measured data of $R_{r s}$ of Lake Chaohu were applied to this model to obtain absorption coefficients. The wavelengths of input $\mathrm{R}_{\mathrm{rs}}$ were at center wavelengths of MODIS bands between 400 and $700 \mathrm{~nm}$, including 413, 443, 469, 488, 531, 551, 555, 645, 667, and $678 \mathrm{~nm}$. The retrieved IOPs included $\mathrm{a}_{\mathrm{ph}}(\lambda)$ and $\mathrm{a}_{\mathrm{dg}}(\lambda)$ of these wavelengths. Figure 9 shows the comparison of retrieved and measured $\mathrm{a}_{\mathrm{ph}}$ and $\mathrm{a}_{\mathrm{dg}}$ of the three different types of water. The concentrations of SPM and Chl $a$ are shown in the graphs.
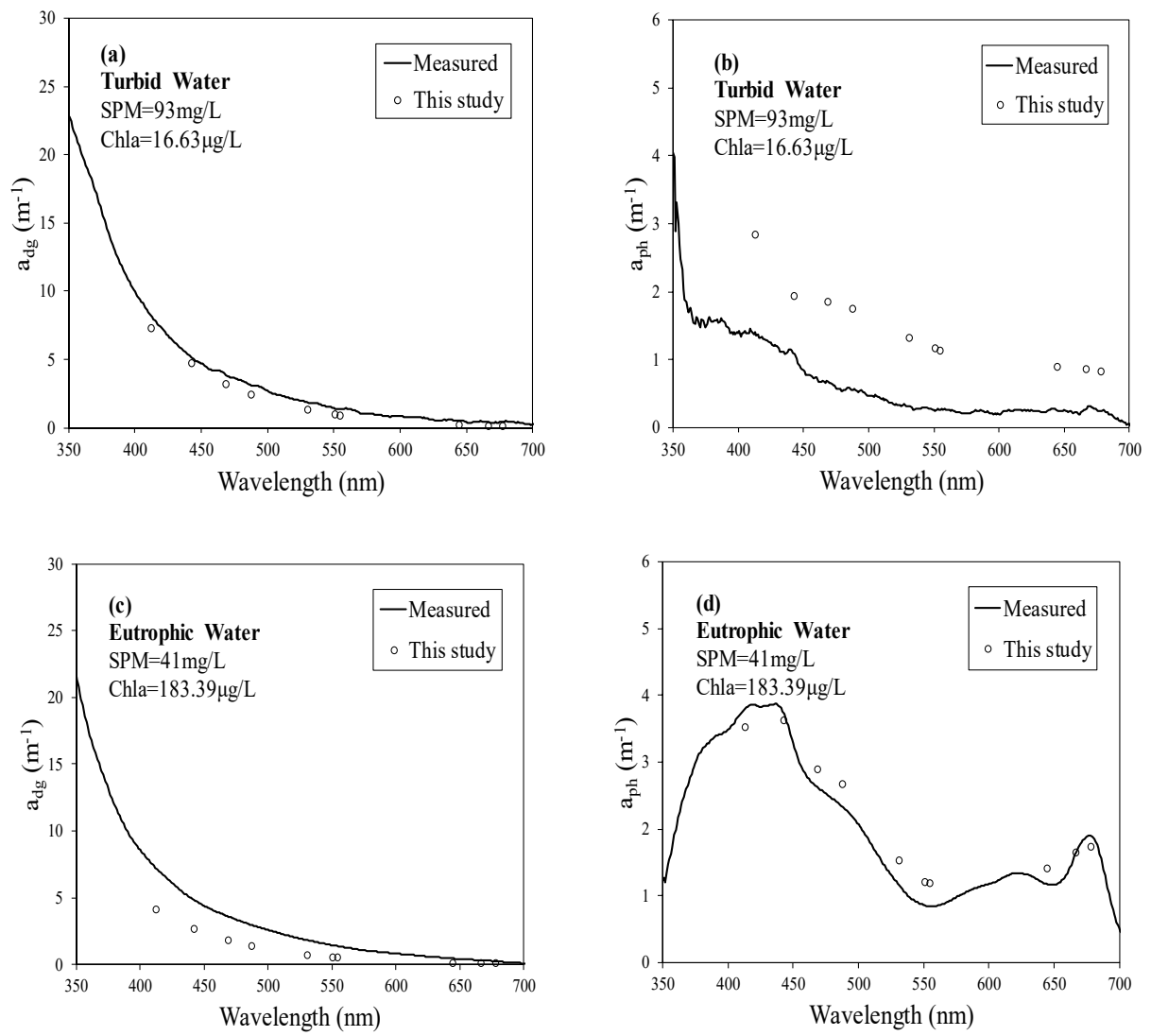

Figure 9. Cont. 

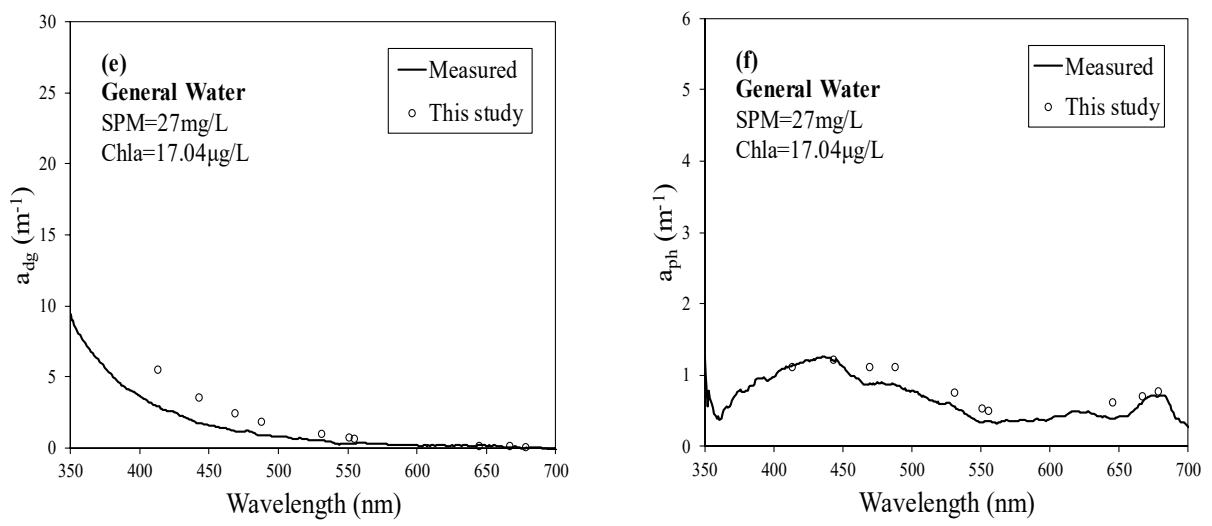

Figure 9. Comparison of derived and measured $\mathrm{a}_{\mathrm{ph}}$ and $\mathrm{a}_{\mathrm{dg}}$ of three different types of water: (a)/(b) turbid water, (c)/(d) eutrophic water, and $(\mathbf{e}) /(\mathbf{f})$ general water.

As shown in Figure 9, this model tends to be more suitable for general waters as it is more effective in obtaining $\mathrm{a}_{\mathrm{ph}}$ when applied to general water than eutrophic water. The values of obtained $\mathrm{a}_{\mathrm{dg}}$ are closer to those of measured $\mathrm{a}_{\mathrm{dg}}$ than $\mathrm{a}_{\mathrm{ph}}$. Thus, the accuracy of derived $\mathrm{a}_{\mathrm{ph}}$ in all water conditions needs to be improved especially in the case of turbid waters.

\subsection{Derived Values at Typical Wavelengths}

To present a general description of the performance of this algorithm, we used 25 field-measured test samples to derive $\mathrm{a}(\lambda), \mathrm{a}_{\mathrm{ph}}(\lambda)$, and $\mathrm{a}_{\mathrm{dg}}(\lambda)$ at $410 \mathrm{~nm}, 440 \mathrm{~nm}$, and center wavelengths of MODIS bands between 400 and $700 \mathrm{~nm}$, then compared them with measured data. Table 7, Figures 10 and 11 show the results of this analysis.

Table 7. Evaluation of the errors between measured and derived values.

\begin{tabular}{ccc}
\hline Values & MRE (\%) & RMSE (sr ${ }^{-1}$ ) \\
\hline $\mathrm{a}(\lambda)$ & 18.96 & 0.88 \\
$\mathrm{a}_{\mathrm{ph}}(\lambda)$ & 102.04 & 0.52 \\
$\mathrm{a}_{\mathrm{dg}}(\lambda)$ & 30.33 & 1.09 \\
\hline
\end{tabular}

Figure 10 shows the total absorption coefficients of typical wavelengths such as 440,488 , and $555 \mathrm{~nm}$.

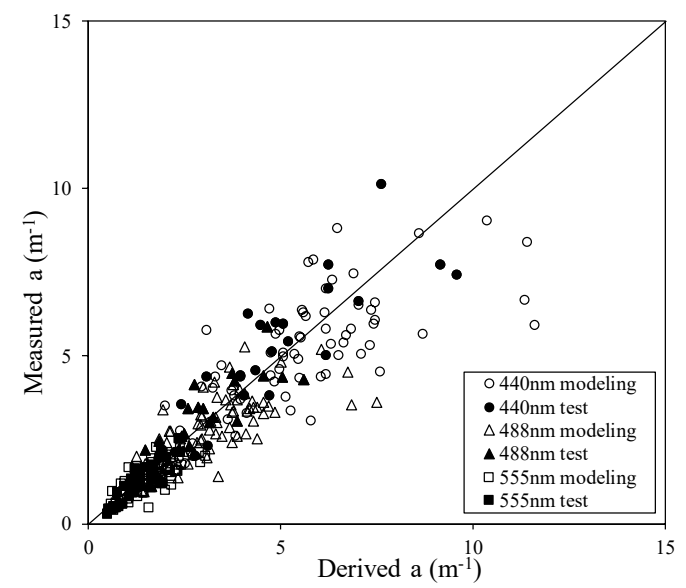

Figure 10. Comparison of improved QAA-derived total absorption coefficients a $(\lambda)$ versus the measured total absorption coefficients a $(\lambda)$ for wavelengths at 440,488 , and $555 \mathrm{~nm}$. 

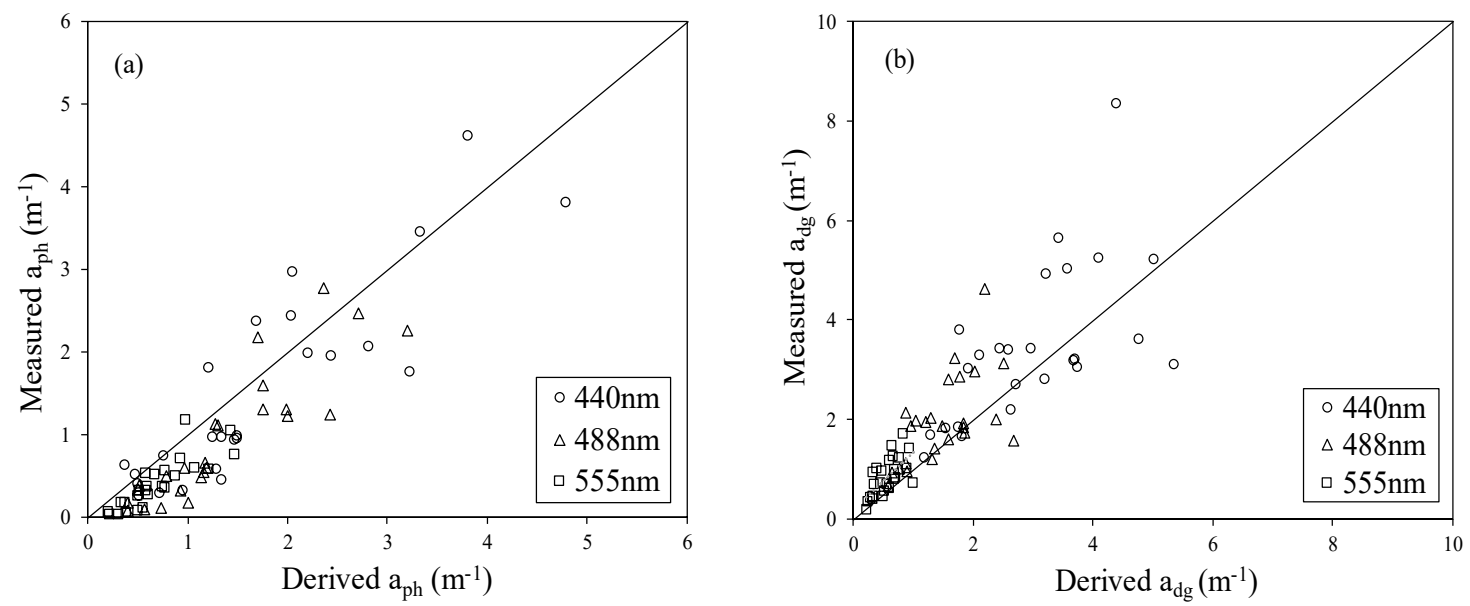

Figure 11. Comparison of derived $(\mathbf{a}) \mathrm{a}_{\mathrm{ph}}(\lambda)$ and (b) $\mathrm{a}_{\mathrm{dg}}(\lambda)$ versus measured values at 440,488 , and $555 \mathrm{~nm}$.

For these wavelengths, the MRE values of test data were $17.68 \%, 19.10 \%$, and $18.71 \%$, and $\mathrm{R}^{2}$ values were $0.74,0.75$, and 0.88 , which indicate a good correlation at the aforementioned wavelengths (Figure 10). Some points were distributed below the 1:1 line, which shows that the derived total absorption coefficients were slightly higher than the measured total absorption coefficients. It was due to the errors between the estimated values of $Y$ and the reference values of $Y$ varying at different conditions. The selection of a reference wavelength may also have had some impact on this situation. Additionally, the errors in measurement of field data can also be responsible for the observed differences. As a result, the accuracy of this model to derive total absorption coefficients needs improvement in these aspects.

The MRE values of derived $\mathrm{a}_{\mathrm{ph}}$ at 440,488 , and $555 \mathrm{~nm}$ were $55.08 \%, 126.59 \%$, and $184.72 \%$, and the $\mathrm{R}^{2}$ values were $0.76,0.78$, and 0.72 , while the MRE values of $\mathrm{a}_{\mathrm{dg}}$ were $24.64 \%, 27.52 \%$, and $32.20 \%$ and the $R^{2}$ values were $0.38,0.36$, and 0.43 (Figure 11). Comparison and analysis showed that the derived $\mathrm{a}_{\mathrm{dg}}$ were moderately smaller than the measured values, but more errors were found at the retrieval of $a_{p h}$. When we compared the inversion of $a_{p h}$ at three wavelengths, we easily concluded that the MREs of values at longer wavelengths were bigger than those at shorter wavelengths. The derived $\mathrm{a}_{\mathrm{ph}}$ were mostly distributed below the 1:1 line, which means that the calculated values were larger than the measured values. Gelbstoff and detritus contribute substantially to the total absorption coefficients at 410 and $440 \mathrm{~nm}$. In the direct decomposition of total $\mathrm{a}(\lambda)$ to $\mathrm{a}_{\mathrm{ph}}(\lambda)$ and $\mathrm{a}_{\mathrm{dg}}(\lambda)$, values of $\zeta$ and $\xi$ were estimated. The errors in these sectors were transferred to the estimated values of $\mathrm{a}_{\mathrm{dg}}(440)$, which then influenced the final inversion of this model. Thus, different wavelengths can be used in future studies to improve the accuracy of decomposition of total absorption coefficients. As this test included a limited range of water samples, it cannot represent the accuracy completely. Further detailed tests with measured data are desired and needed to improve this model to derive $\mathrm{a}_{\mathrm{ph}}$ and $\mathrm{a}_{\mathrm{dg}}$ optimally.

\section{Discussion}

\subsection{Error Propagation}

Error propagation means errors that may occur at each step have varying effects on the analysis results. The errors in each step propagate to the next step in the step-by-step process. We analyzed the error propagation of some steps of this algorithm by using modeling data (Table 8). This part shows the performance assessment of absorption coefficients at wavelengths $410,440 \mathrm{~nm}$, and the center wavelengths of MODIS bands between 400 and $700 \mathrm{~nm}$. 
Table 8. Error propagation of steps of the improved QAA.

\begin{tabular}{|c|c|c|c|c|c|}
\hline Step & Formulas & Approach & $\begin{array}{c}\text { Relative } \\
\text { Errors Range }\end{array}$ & MRE & $\begin{array}{l}\text { RMSE } \\
\left(\mathrm{sr}^{-1}\right)\end{array}$ \\
\hline 2 & $\mathrm{a}(748)=a_{w}(748)$ & Empirical & $\begin{array}{l}-14.26 \% \\
\sim 12.61 \%\end{array}$ & $3.68 \%$ & 0.12 \\
\hline 4 & $\begin{array}{c}\mathrm{Y}= \\
0.0103 * \exp \left[0.0121\left(R_{r s}(555) / R_{r s}(748)\right)^{2}-0.3452\left(R_{r s}(555) / R_{r s}(748)\right)+\right. \\
4.7784]+1.6386\end{array}$ & Empirical & $\begin{array}{r}-34.14 \% \\
\sim 129.31 \%\end{array}$ & $19.31 \%$ & 0.72 \\
\hline a & & & & $26.36 \%$ & 1.09 \\
\hline 7 & $\zeta=\frac{a_{\mathrm{ph}}(410)}{a_{\mathrm{ph}}(440)}=\frac{2.8395}{r_{r_{\mathrm{s}}}(645) / r_{\mathrm{rs}}(678)}-1.2933$ & Empirical & $\begin{array}{l}-25.91 \% \\
46.19 \%\end{array}$ & $12.62 \%$ & 0.15 \\
\hline 8 & $\xi=\frac{a_{d g}(410)}{a_{d g}(440)}=\exp [S(440-410)]$ & Semi-analytical & $\begin{array}{l}-8.19 \% \\
\sim 8.12 \%\end{array}$ & $2.74 \%$ & 0.05 \\
\hline$a_{d g} 440$ & & & & $28.25 \%$ & 1.50 \\
\hline$a_{d g}$ & & & & $35.07 \%$ & 1.22 \\
\hline$a_{p h}$ & & & & $133.10 \%$ & 1.07 \\
\hline
\end{tabular}

As the table suggests, all the errors were from the empirical and semi-analytical algorithms. Through the steps to retrieve the total absorption coefficients, the MRE between calculated $Y$ values and reference $Y$ values was approximately 19.31\%, which was due to the relationship of $\mathrm{R}_{\mathrm{rs}}$, SPM concentration, and the value of $\mathrm{Y}$. Therefore, this step consequently led to the errors of the calculated total absorption. The retrieval of $\mathrm{a}_{\mathrm{ph}}(410) / \mathrm{a}_{\mathrm{ph}}(440)$ and $\mathrm{a}_{\mathrm{dg}}(410) / \mathrm{a}_{\mathrm{dg}}(440)$ had errors of $12.62 \%$ and $2.74 \%$, respectively, which showed that the main source of the errors of $\mathrm{a}_{\mathrm{dg}}$ was due to the calculation of $\mathrm{a}_{\mathrm{dg}}(440)$ and then extended to $\mathrm{a}_{\mathrm{dg}}$ in the full wavelength range. Also, the errors of derived total absorption coefficients affected the accuracy of $\mathrm{a}_{\mathrm{ph}}$ and $\mathrm{a}_{\mathrm{dg}}$. At the same time, because the values of measured $\mathrm{a}_{\mathrm{ph}}$ at longer wavelengths and some samples were small, the MREs increased, thereby influencing the total MRE of $\mathrm{a}_{\mathrm{ph}}$.

\subsection{Comparison with $Q A A$}

As mentioned, QAA did not function well when applied to Lake Chaohu (Figure 12). In the case below, especially at a wavelength longer than $600 \mathrm{~nm}$, the values of $\mathrm{a}_{\mathrm{ph}}$ are almost less than zero, which was impossible for Lake Chaohu. Therefore, improving this algorithm is necessary.
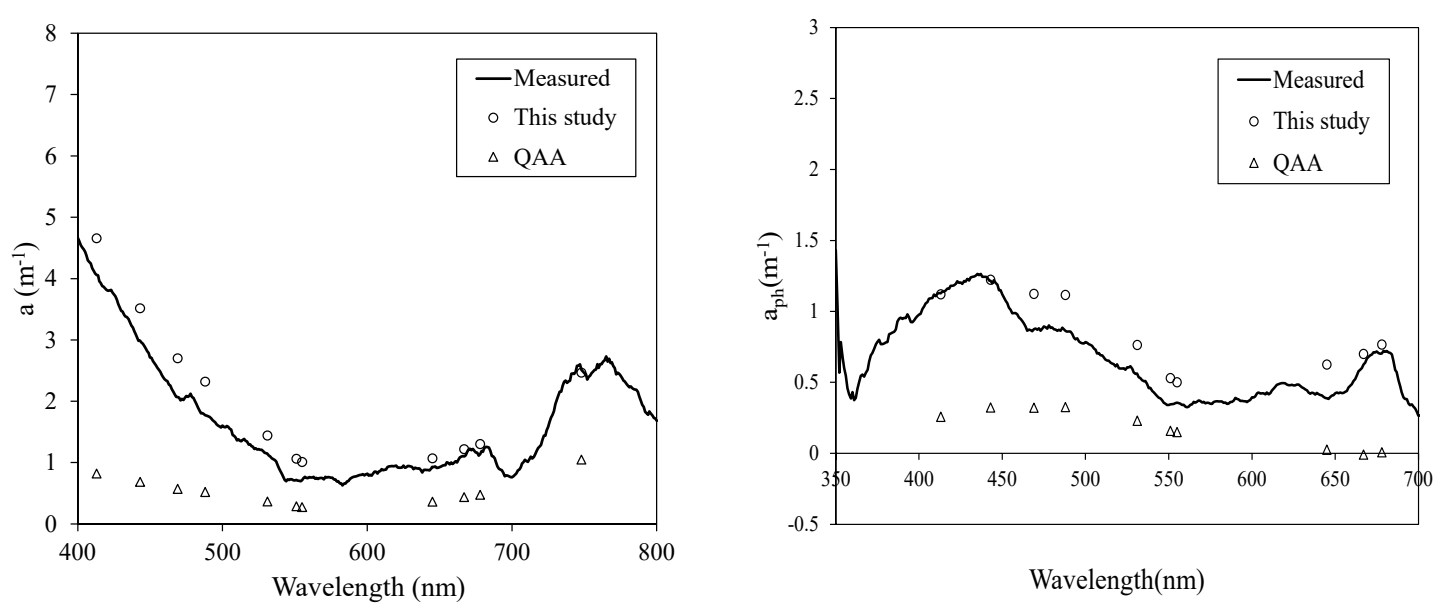

Figure 12. Comparison of QAA-retrieved $\mathrm{a}\left(\mathrm{a}_{\mathrm{ph}}\right)$ versus measured data and the improved QAA-retrieved $\mathrm{a}\left(\mathrm{a}_{\mathrm{ph}}\right)$ versus measured data.

The algorithm in this article was further validated by the measured dataset collected in Lake Chaohu. The version, QAA_v6, tended to be more suitable for turbid coastal waters, so it was also applied to the same dataset (Figure 13). The assessment results for retrieved absorption coefficients at some special wavelengths are summarized in Table 9. The RMSEs and MREs for the algorithm in this study were in the range of $0.21-1.06 \mathrm{sr}^{-1}$ and $17.27-54.85 \%$, while those of QAA_v6 were $0.99-4.17 \mathrm{sr}^{-1}$ 
and 56.93-73.51\%, respectively. Specifically, the RMSEs and MREs of the QAA_v6 were larger than those of the algorithm in this study. The values of total absorption coefficients derived from QAA_v6 were much smaller than measured data. The larger RMSEs' and MREs' values derived from QAA_v6 were mainly because of a short reference wavelength and inappropriate estimated formulas that do not work for turbid Case 2 waters. The $\mathrm{a}_{\mathrm{ph}}(443)$ was also retrieved based on QAA_v6 for comparison. Scatterplots of derived and measured $\mathrm{a}_{\mathrm{ph}}(443)$ are shown in Figure 13, and the evaluation indices are also demonstrated in Table 9. In general, we can conclude that the algorithm in this research had smaller errors of RMSE and MRE of $0.60 \mathrm{sr}^{-1}$ and $54.85 \%$, respectively, compared with those of $1.46 \mathrm{sr}^{-1}$ and $56.93 \%$ from the $\mathrm{a}_{\mathrm{ph}}(443)$ estimated by QAA_v6. However, because the $\mathrm{a}_{\mathrm{ph}}$ derived from the algorithm in this study tended to be larger than measured data, at some points, $a_{\mathrm{ph}}(443)$ derived from QAA-v6 were closer to measured data than those of this study.
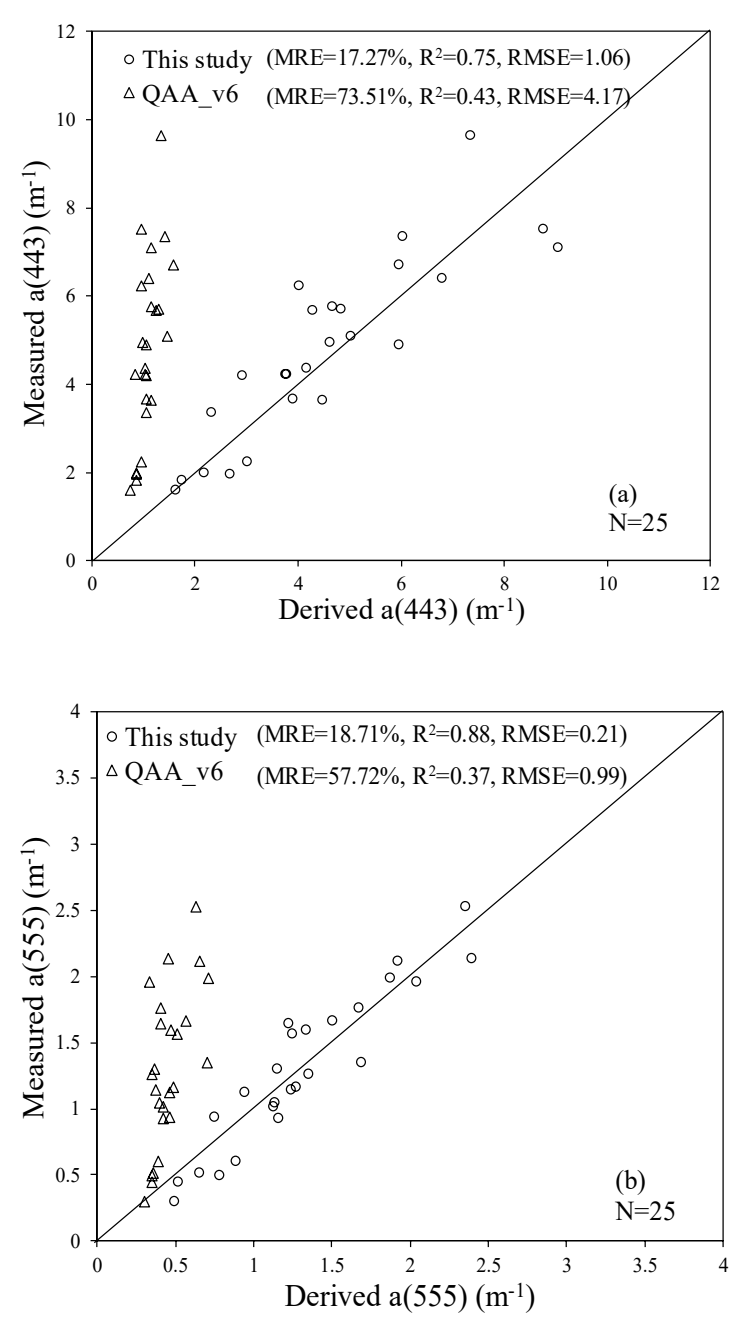

Figure 13. Cont. 


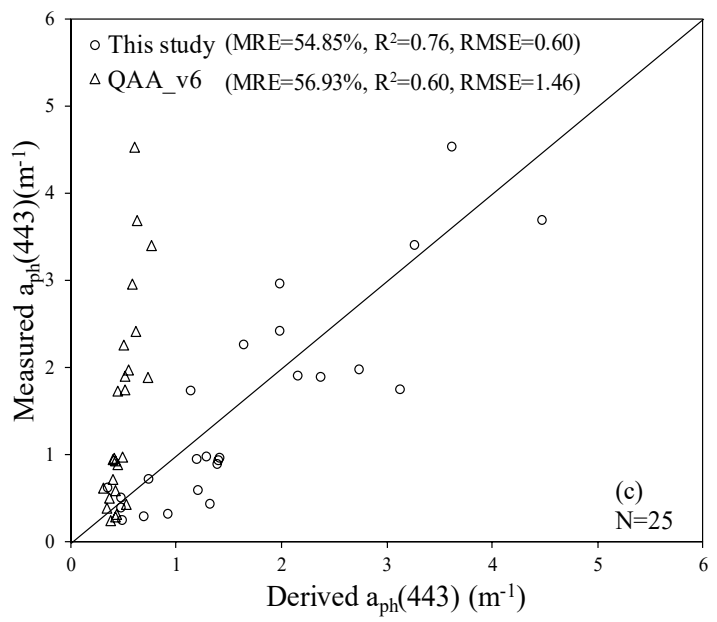

Figure 13. Comparison of measured and derived total absorption coefficients at (a) $443 \mathrm{~nm}$ and (b) $555 \mathrm{~nm}$, and $\mathrm{a}_{\mathrm{ph}}$ at (c) $443 \mathrm{~nm}$ for applying the algorithm in this study and QAA_v6, respectively.

Table 9. Accuracy assessment of the algorithm in this study and QAA_v6.

\begin{tabular}{cccccc}
\hline & Algorithms & $\mathbf{N}$ & MRE & $\mathbf{R}^{\mathbf{2}}$ & RMSE (sr $\left.^{-1}\right)$ \\
\hline \multirow{2}{*}{$\mathrm{a}(443)$} & this study & 25 & $17.27 \%$ & 0.75 & 1.06 \\
& QAA_v6 & 25 & $73.51 \%$ & 0.43 & 4.17 \\
\hline \multirow{2}{*}{$\mathrm{a}(555)$} & this study & 25 & $18.71 \%$ & 0.88 & 0.21 \\
& QAA_v6 & 25 & $57.72 \%$ & 0.37 & 0.99 \\
\hline \multirow{2}{*}{$\mathrm{a}_{\mathrm{ph}}(443)$} & this study & 25 & $54.85 \%$ & 0.76 & 0.60 \\
& QAA_v6 & 25 & $56.93 \%$ & 0.60 & 1.46 \\
\hline
\end{tabular}

\subsection{MODIS Data Inversion}

We used the algorithm proposed in this study to calculate the $\mathrm{a}_{\mathrm{ph}}$ at 443,645 , and $678 \mathrm{~nm}$ of Lake Chaohu in 2013 by applying corrected MOD09 data (Figure 14). Because of the difference of bands, we used MODIS bands 8 and 9 data to be the input parameters at 410 and $440 \mathrm{~nm}$. The missing parts of the image were due to saturation that usually occurs at long wavelengths of 1-km resolution of this product. Even though there were some problems with this product, we still could verify the general seasonal changes of Lake Chaohu. Generally, $a_{\mathrm{ph}}$ varied largely in Lake Chaohu. High $\mathrm{a}_{\mathrm{ph}}$ was observed in the northwestern parts of Lake Chaohu in the summer and autumn, and $\mathrm{a}_{\mathrm{ph}}$ were relatively lower in the spring and winter. This pattern is consistent with the known phenomenon. Cyanobacteria blooms occur mainly in the western area in the summer, and the large amount of cyanobacteria in the western part is due to the exogenous load of the lakes mainly from the northwest of the basin. The suitable temperature of $20-34{ }^{\circ} \mathrm{C}$ in summer, the higher $\mathrm{N}$ and $\mathrm{P}$ concentrations, the higher $\mathrm{PH}$ value, the appropriate light intensity, and other environmental conditions provide the perfect environment for the growth of cyanobacteria. Therefore, $\mathrm{a}_{\mathrm{ph}}$ tends to be higher in the western part in summer. 

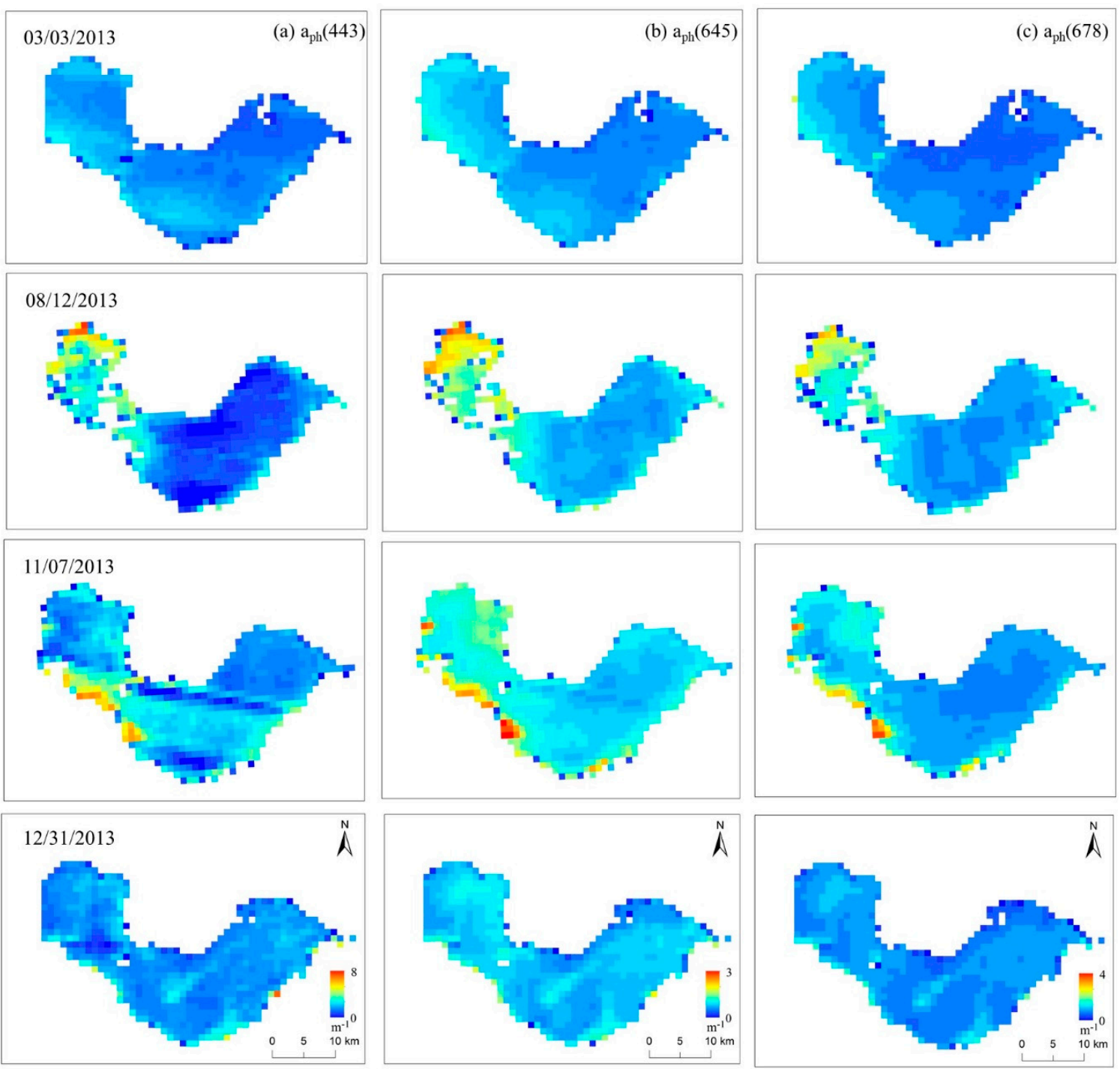

Figure 14. The calculated $a_{p h}$ at (a) 443, (b) 645, (c) $678 \mathrm{~nm}$ in four seasons of Lake Chaohu.

\section{Conclusions}

Based on the field-measured data of Lake Chaohu, this study improved the QAA algorithm to provide an effective inversion of the IOPs of Lake Chaohu according to MODIS bands. The appropriate reference wavelength was shifted to $748 \mathrm{~nm}$ according to the measured data from the lake, and the applicable empirical model of the $Y$ value was established by building models with SPM concentration and $R_{\mathrm{rs}}$. The $\mathrm{a}_{\mathrm{dg}}$ and $\mathrm{a}_{\mathrm{ph}}$ were also derived by changing important parameters according to Lake Chaohu. To test the accuracy of this model, we applied this algorithm to a test dataset. This algorithm tends to be more suitable for general waters. It works better in the retrieval of total absorption coefficients in the condition of Lake Chaohu than original QAA and QAA_v6 do. The derived $\mathrm{a}_{\mathrm{dg}}$ of this algorithm tend to be smaller than measured data and the derived $\mathrm{a}_{\mathrm{ph}}$ tend to be bigger than measured values at some points. We also used the corrected MOD09 data to calculate $a_{\mathrm{ph}}$ at 443, 645, and $678 \mathrm{~nm}$ by the model proposed in this study. It shows that, in summer and autumn, $\mathrm{a}_{\mathrm{ph}}$ tend to be higher in the northwestern part of Lake Chaohu, which is similar to the previous studies.

More independent tests with field measurement are required for validating and improving the algorithm. This algorithm needs to be improved in several aspects. First, the accuracy of the empirical model for calculating the $Y$ value can be developed because it is one of the errors of the derived total absorption coefficients. Secondly, basic wavelengths can be changed to derive accurate $\mathrm{a}_{\mathrm{ph}}$ and $\mathrm{a}_{\mathrm{dg}}$. 
Combining the measured backscattering coefficients with the derived backscattering coefficients in future research will help improve the accuracy of this algorithm.

Author Contributions: Conceptualization, Y.Z.; Data curation, Y.J.; Formal analysis, M.H.; Funding acquisition, Y.Z. and R.M.; Investigation, Q.C.; Methodology, Q.C.; Project administration, Y.Z.; Software, Q.C. and M.H.; Supervision, R.M.; Writing—original draft, Q.C.; Writing—review \& editing, Q.C. and Y.J. All authors have read and agreed to the published version of the manuscript.

Funding: This work was funded by the National Natural Science Foundation of China (Grant No. 41671371) and Jiangsu Provincial Key Research and Development Program (BE2019774).

Acknowledgments: Field data were provided by the Scientific Data Sharing Platform for Lake and Watershed, Nanjing Institute of Geography and Limnology, Chinese Academy of Sciences.

Conflicts of Interest: The authors declare no conflict of interest.

\section{References}

1. Mobley, C.D. Light and Water: Radiative Transfer in Natural Waters; Academic Press: Cambridge, MA, USA, 1994.

2. Ma, R.; Tang, J.; Dai, J. Bio-optical model with optimal parameter suitable for Taihu Lake in water colour remote sensing. Int. J. Remote Sens. 2006, 27, 4305-4328. [CrossRef]

3. Carder, K.; Chen, F.; Cannizzaro, J.; Campbell, J.; Mitchell, B. Performance of the MODIS semi-analytical ocean color algorithm for chlorophyll-a. Adv. Space Res. 2004, 33, 1152-1159. [CrossRef]

4. Gons, H.J. Optical teledetection of chlorophyll a in turbid inland waters. Environ. Sci. Technol. 1999, 33, 1127-1132. [CrossRef]

5. Carder, K.L.; Chen, F.; Lee, Z.; Hawes, S.; Kamykowski, D. Semianalytic Moderate-Resolution Imaging Spectrometer algorithms for chlorophyll a and absorption with bio-optical domains based on nitrate-depletion temperatures. J. Geophys. Res. Oceans 1999, 104, 5403-5421. [CrossRef]

6. Hoge, F.E.; Lyon, P.E. Satellite retrieval of inherent optical properties by linear matrix inversion of oceanic radiance models: An analysis of model and radiance measurement errors. J. Geophys. Res. Oceans 1996, 101, 16631-16648. [CrossRef]

7. Hoge, F.E.; Lyon, P.E. Spectral parameters of inherent optical property models: Method for satellite retrieval by matrix inversion of an oceanic radiance model. Appl. Opt. 1999, 38, 1657-1662. [CrossRef]

8. Doerffer, R.; Helmut, S. Neural network for retrieval of concentrations of water constituents with the possibility of detecting exceptional out of scope spectra. In Proceedings of the IGARSS 2000. IEEE 2000 International Geoscience and Remote Sensing Symposium. Taking the Pulse of the Planet: The Role of Remote Sensing in Managing the Environment Proceedings, Piscataway, NJ, USA, 24-28 July 2000; pp. 714-717.

9. Lee, Z.; Carder, K.L.; Arnone, R.A. Deriving inherent optical properties from water color: A multiband quasi-analytical algorithm for optically deep waters. Appl. Opt. 2002, 41, 5755-5772. [CrossRef]

10. Lee, Z.; Lubac, B.; Werdell, J. Update of the Quasi-Analytical Algorithm (QAA_v6) [R/OL]. Available online: http://www.ioccg.org/groups/Software_OCA/QAA_v6_2014209.pdf (accessed on 1 November 2014).

11. Hu, L.-B.; Liu, Z.-S. Deriving Absorption Coefficients from Remote Sensing Reflectance Using the Quasi-Analytical Algorithm (QAA) in the Yellow Sea. Period. Ocean Univ. China 2007, S2, 154-160.

12. Wang, W.-Q.; Dong, -Q.; Shang, S.-L.; Wu, J.-Y.; Lee, Z.-P. An evaluation of two semi-analytical ocean color algorithms for waters of the South China Sea. J. Trop. Oceanogr. 2009, 28, 35-42.

13. Hao, Y.-L.; Cao, W.-X.; Cui, T.-W.; Zhang, J. The retrieval of oceanic inherent optical properties based on semianalytical algorithm during the red ride. Acta Oceanol. Sin. 2011, 33, 52-65.

14. Gordon, H.; More, A. Remote assessment of ocean color for interpretation of satellite visible imagery, a review. In Lecture Notes on Coastal and Estuarine Studies; Barber, R.T., Mooers, C.N.K., Bowman, M.J., Zeitschel, B., Eds.; Springer: New York, NY, USA, 1983.

15. Le, C.-F.; Li, Y.-M.; Zha, Y.; Sun, D.-Y.; Lu, H. Simulation of backscattering properties of Taihu Lake. Adv. Water Sci. 2009, 20, 707-713.

16. Le, C.-F.; Li, Y.-M.; Zha, Y.; Sun, D.; Yin, B. Validation of a quasi-analytical algorithm for highly turbid eutrophic water of Meiliang Bay in Taihu Lake, China. IEEE Trans. Geosci. Remote Sens. 2009, 47, 2492-2500.

17. Xie, F.; Guo, Z.; Tian, Y.; Liu, C.; Lei, X. Retrieving Inherent Optical Properties of Lake Kuncheng based on Quasi-Analytical Algorithm. Remote Sens. Technol. Appl. 2015, 30, 242-250. 
18. Jiang, L.; Zhao, D.; Wang, L.; Wang, X. Methods and Research Progress on Backscattering Coefficient in the Water. Remote Sens. Technol. Appl. 2013, 28, 150-156.

19. Wei, Y.; Matsushita, B.; Jin, C.; Yoshimura, K.; Fukushima, T. Retrieval of Inherent Optical Properties for Turbid Inland Waters from Remote-Sensing Reflectance. IEEE Trans. Geosci. Remote Sens. 2013, 51, 3761-3773.

20. Li, S.; Song, K.; Mu, G.; Ying, Z.; Ren, J. Evaluation of the Quasi-Analytical Algorithm (QAA) for Estimating Total Absorption Coefficient of Turbid Inland Waters in Northeast China. IEEE J. Sel. Top. Appl. Earth Obs. Remote Sens. 2016, 9, 4022-4036. [CrossRef]

21. Chen, X.; Yang, X.; Dong, X.; Liu, E. Environmental changes in Chaohu Lake (southeast, China) since the mid 20th century: The interactive impacts of nutrients, hydrology and climate. Limnol. Ecol. Manag. Inland Waters 2013, 43, 10-17. [CrossRef]

22. Tu, Q.; Gu, D.; Yi, C.; Xu, Z.; Han, G. The Researches on the Lake Chaohu Eutrophication; Publisher of University of Science and Technology of China: Hefei, China, 1990.

23. Qin, N.; He, W.; Kong, X.-Z.; Liu, W.-X.; He, Q.-S.; Yang, B.; Ouyang, H.-L.; Wang, Q.-M.; Xu, F.-L. Atmospheric partitioning and the air-water exchange of polycyclic aromatic hydrocarbons in a large shallow Chinese lake (Lake Chaohu). Chemosphere 2013, 93, 1685-1693. [CrossRef]

24. Yang, L.; Lei, K.; Meng, W.; Fu, G.; Yan, W. Temporal and spatial changes in nutrients and chlorophyll- $\alpha$ in a shallow lake, Lake Chaohu, China: An 11-year investigation. J. Environ. Sci. 2013, 25, 1117-1123. [CrossRef]

25. Jiang, Y.-J.; He, W.; Liu, W.-X.; Qin, N.; Ouyang, H.-L.; Wang, Q.-M.; Kong, X.-Z.; He, Q.-S.; Yang, C.; Yang, B. The seasonal and spatial variations of phytoplankton community and their correlation with environmental factors in a large eutrophic Chinese lake (Lake Chaohu). Ecol. Indic. 2014, 40, 58-67. [CrossRef]

26. Mueller, J.L.; Morel, A.; Frouin, R.; Davis, C.; Arnone, R.; Carder, K.; Lee, Z.P.; Steward, R.G.; Hooker, S.; Mobley, C.D.; et al. Ocean Optics Protocols for Satellite Ocean Color Sensor Validation, Revision 4: Radiometric Measurements and Data Analysis Protocols; National Aeronautical and Space asministration, Goddard Space Flight Center: Greenbelt, MD, USA, 2003; Volume 3.

27. Mobley, C.D. Estimation of the remote-sensing reflectance from above-surface measurements. Appl. Opt. 1999, 38, 7442-7455. [CrossRef] [PubMed]

28. Werdell, P.J.; Franz, B.A.; Bailey, S.W.; Feldman, G.C.; Boss, E.; Brando, V.E.; Dowell, M.; Hirata, T.; Lavender, S.J.; Lee, Z.P. Generalized ocean color inversion model for retrieving marine inherent optical properties. Appl. Opt. 2013, 52, 2019-2037. [CrossRef] [PubMed]

29. Jiang, G.; Ma, R.; Loiselle, S.A.; Duan, H. Optical approaches to examining the dynamics of dissolved organic carbon in optically complex inland waters. Environ. Res. Lett. 2012, 7, 034014. [CrossRef]

30. Bricaud, A.; Morel, A.; Prieur, L. Absorption by Dissolved Organic Matter of the Sea (Yellow Substance) in the UV and Visible Domains. Limnol. Oceanogr. 1981, 26, 43-53. [CrossRef]

31. Zhou, Y.; Zhang, Y.; Shi, K.; Cheng, N.; Liu, X.; Duan, H. Lake Taihu, a large, shallow and eutrophic aquatic ecosystem in China serves as a sink for chromophoric dissolved organic matter. J. Great Lakes Res. 2015, 41, 597-606. [CrossRef]

32. Khandelwal, A.; Karpatne, A.; Marlier, M.E.; Kim, J.; Lettenmaier, D.P.; Kumar, V. An approach for global monitoring of surface water extent variations in reservoirs using MODIS data. Remote Sens. Environ. 2017, 202, 113-128. [CrossRef]

33. Chernetskiy, M.; Shevyrnogov, A.; Shevnina, S.; Vysotskaya, G.; Sidko, A. Investigations of the Krasnoyarsk Reservoir waters based on the multispectral satellite data. Adv. Space Res. 2009, 43, 206-213. [CrossRef]

34. Klein, I.; Gessner, U.; Dietz, A.J.; Kuenzer, C. Global WaterPack-A $250 \mathrm{~m}$ resolution dataset revealing the daily dynamics of global inland water bodies. Remote Sens. Environ. 2017, 198, 345-362. [CrossRef]

35. Hou, X.; Feng, L.; Duan, H.; Chen, X.; Sun, D.; Shi, K. Fifteen-year monitoring of the turbidity dynamics in large lakes and reservoirs in the middle and lower basin of the Yangtze River, China. Remote Sens. Environ. 2017, 190, 107-121. [CrossRef]

36. Song, K.; Ma, J.; Wen, Z.; Fang, C.; Shang, Y.; Zhao, Y.; Wang, M.; Du, J. Remote estimation of Kd (PAR) using MODIS and Landsat imagery for turbid inland waters in Northeast China. ISPRS J. Photogramm. Remote Sens. 2017, 123, 159-172. [CrossRef]

37. Wang, S.-L.; Li, J.-S.; Zhang, B.; Shen, Q.; Zhang, F.-F.; Lu, Z.-Y. A simple correction method for the MODIS surface reflectance product over typical inland waters in China. Int. J. Remote Sens. 2016, 37, 6076-6096.

38. Wang, M.; Shi, W. The NIR-SWIR combined atmospheric correction approach for MODIS ocean color data processing. Opt. Express 2007, 15, 15722-15733. [CrossRef] [PubMed] 
39. Gordon, H.R.; Brown, O.B.; Evans, R.H.; Brown, J.W.; Smith, R.C.; Baker, K.S.; Clark, D.K. A semianalytic radiance model of ocean color. J. Geophys. Res. Atmos. 1988, 93, 10909-10924. [CrossRef]

40. Morel, A. Optical modeling of the upper ocean in relation to its biogenous matter content (case I waters). J. Geophys. Res. Oceans 1988, 93, 10749-10768. [CrossRef]

41. Lee, Z.; Carder, K.L.; Mobley, C.D.; Steward, R.G.; Patch, J.S. Hyperspectral remote sensing for shallow waters: 2. Deriving bottom depths and water properties by optimization. Appl. Opt. 1999, 38, 3831-3843. [CrossRef] [PubMed]

42. Pope, R.M.; Fry, E.S. Absorption spectrum (380-700 nm) of pure water. II. Integrating cavity measurements. Appl. Opt. 1997, 36, 8710-8723. [CrossRef] [PubMed]

43. Zhang, H.; Huang, J.-Z.; Li, Y.-M.; Xu, Y.-F.; Liu, Z.-H.; Xu, X. Monitoring the total suspended matter of Lake Chaohu based on quasi-analytical algorithm. Environ. Sci. 2012, 33, 429-435.

44. Li, S.-J.; Wang, X.-J. Relationship between Suspended Matter Concentration and Spectral Reflectance of Chao Lake. Urban Environ. Urban Ecol. 2003, 6, 66-68.

45. Song, Q.-J.; Tang, J.-W. The study on the scattering properties in the Huanghai Sea and East China Sea. Acta Oceanol. Sin. 2006, 28, 56-63.

46. Sun, D.-Y.; Li, Y.-M.; Le, C.-F.; Gong, S.-Q.; Wang, H.-J.; Wu, L.; Huang, C.-C. Scattering characteristics of Taihu Lake and its relationship models with suspended particle concentration. Environ. Sci. 2007, 28, 2688-2694.

47. Miller, R.L.; McKee, B.A. Using MODIS Terra $250 \mathrm{~m}$ imagery to map concentrations of total suspended matter in coastal waters. Remote Sens. Environ. 2004, 93, 259-266. [CrossRef]

48. Shi, K.; Zhang, Y.; Zhu, G.; Liu, X.; Zhou, Y.; Xu, H.; Qin, B.; Liu, G.; Li, Y. Long-term remote monitoring of total suspended matter concentration in Lake Taihu using $250 \mathrm{~m}$ MODIS-Aqua data. Remote Sens. Environ. 2015, 164, 43-56. [CrossRef]

49. Doxaran, D.; Froidefond, J.-M.; Lavender, S.; Castaing, P. Spectral signature of highly turbid waters: Application with SPOT data to quantify suspended particulate matter concentrations. Remote Sens. Environ. 2002, 81, 149-161. [CrossRef]

50. Kutser, T.; Metsamaa, L.; Vahtmäe, E.; Aps, R. Operative monitoring of the extent of dredging plumes in coastal ecosystems using MODIS satellite imagery. J. Coast. Res. 2007, Special Issue 50, 180-184.

51. Safonov, M.; Chiang, R. Model reduction for robust control: A Schur relative error method. Int. J. Adapt. Control Signal Process. 1988, 2, 259-272. [CrossRef]

52. Mentaschi, L.; Besio, G.; Cassola, F.; Mazzino, A. Problems in RMSE-based wave model validations. Ocean Model. 2013, 72, 53-58. [CrossRef]

(C) 2020 by the authors. Licensee MDPI, Basel, Switzerland. This article is an open access article distributed under the terms and conditions of the Creative Commons Attribution (CC BY) license (http://creativecommons.org/licenses/by/4.0/). 